\title{
Relationship Between the structure of Newly Synthesized derivatives of 1,3,4-oxadiazole Containing 2-Methylphenol and their Antioxidant and Antibacterial Activities
}

\author{
SHAIMAA ABED SAOUD ${ }^{1}$, KHALID FAHAD ALI ${ }^{\star 1}$ and RAIED MUSTAFA SHAKIR ${ }^{\star 1}$ \\ 'Department of Chemistry, Ibn Al-haitham, University of Baghdad, Baghdad 61023, Iraq. \\ ${ }^{*}$ Corresponding author E-mail address: shaimaachem @ hotmail.com \\ http://dx.doi.org/10.13005/ojc/330423
}

(Received: June 03, 2017; Accepted: June 14, 2017)

\begin{abstract}
1,3,4-oxadiazole-5-thion ring(2) successfully formed at position six of 2-methylphenol and five of their thioalkyl(3a-e). Furthermore 6-(5-(Aryl)-1,3,4-oxadiazol-2-yl)-2-methylphenol (5a-i) were formed at position six by two method. The first method was from cyclization their correspondinghydrazones(4a-e) of 2-hydroxy-3-methylbenzohydrazide (1)using bromine in glacial acetic acid. The second method was from cyclization the hydrazide with aryl carboxylic acid in the presence of phosphorusoxy chloride. The newly synthesized compounds were characterized from their IR, NMR and mass spectra. The antioxidant properties of these compounds were screened by 2,2-Diphenyl-1-picrylhydrazide (DPPH) and ferric reducing antioxidant power (FRAP) assays. Compound (4d) and (5h) exhibited significant antioxidant properties in both assays, compared to ascorbic acid, while compound (4e) exhibited slightly less antioxidant properties than ascorbic acid. Antibacterial activity was tested for the twenty one compounds against eight microorganisms (gram negative and gram positive). Compound (4d)and (5d) exhibited significant antibacterial activities compared to Amoxicillin and Kanamycin as antibiotic standards.
\end{abstract}

Keywords: 2-methylphenol, hindered phenol, 1,3,4-oxadiazole, antioxidant, antibacterial

\section{INTRODUCTION}

The effects of free radicals and reactive oxygen species (ROS) embroiled in causes severe damages for biomolecules cells ${ }^{1}$. These damages grounds of several diseases such as cancers ${ }^{2}$ inflammatory ${ }^{3}$, chronic diseases ${ }^{4}$ besides to degenerative diseases ${ }^{5}$.Antioxidants among the significant defense agents against free radicals damages by prevent formation free radicals or elimination of its damages. Antioxidant compounds are effective in the treatment and prevention of several diseases such anti-inflammatory ${ }^{6}$ and anticancer ${ }^{7}$. Furthermore, the digestive, antiinflammatory, anti-necrotic, neuroprotective, and hepatoprotective medicines possess an antioxidant capability ${ }^{8}$. However, the antioxidants have been exhibited some potential adverse health effects. ${ }^{9}$ 
The free radical scavenger donates a proton to the reactive radical and terminated it or breaks the chain reaction. After donating a proton were converted to a stable radical; this stability enhances the property of the antioxidant ${ }^{10}$. Large number of literature reviews emphasized strongly at the relationship between the structure and the antioxidant efficiency. Extent of delocalization, multiple phenolic hydroxyl groups, and steric hindrance of phenol besides the type and positions of the substituted group could play an important role to enhance the antioxidant ability ${ }^{10-15}$. This shedlight on the close relationship between the chemical structure and antioxidant ability.

Recently, 1,3,4-oxadiazoles derivatives exhibited broad spectrum of biological activates likewise antitumor ${ }^{16}$, antiproliferative ${ }^{17}, \alpha$-glucosidase inhibitors ${ }^{18}$, anti-inflammatory ${ }^{19-21}$, antibacterial ${ }^{22}$, antifungals ${ }^{23,24}$ as well the antioxidant ability ${ }^{25-27}$. Many researchers have reported that the substituent group at ortho of phenols possess directly control to improve or disprove the antioxidant capacity ${ }^{28-32}$. This work presented that formation 1,3,4-oxadiazole ring at position six cause increase both the steric hindrance and the resonance effect. The 1,3,4oxadiazoles-5-thione were synthesized in addition to a series of their alkyl as well the series of 1,3,4oxadiazole-5-Aryl have been investigated for their antioxidant capacity.

\section{EXPERIMENTAL}

\section{General Chemistry}

The chemicals used for synthesis were purchased from Sigma-Aldrich, Fisher and and Merck. Melting point was determined by open capillary tube method using OMEGA MPS10 apparatus and is uncorrected. Purities of compounds were checked with a thin layer chromatography (Silica gel TLC) plate's brand Merck, and the spot located with UV lights and iodine vapors. The IR spectrums were obtained with Perkin Elmer 400 Fourier Transform Infrared (FTIR) Spectrometer (the central service laboratory, College of education for pure science-Ibn Al-haitham). NMR spectra were recorded on Bruker AVN 400 (University of Malaya, Malaysia) and $300 \mathrm{MHz}$ (AL- Bayt University, Jordan), DMSO- $d_{6}$ used as a solvent with TMS as internal standard, measurements were The mass spectrum was recorded using Shima dzu GCMS-QP2010Ultra (Al-Mustansiriyah University, College of Science, Department of Chemistry), UV spectroscopy Power Wave X340,BIO-TEK instrument INC was used to recorded the FRAP Assay and DPPH assay.

\section{Synthesis of 2-hydroxy-3-methyl benzo hydrazide}

Ethyl 2-hydroxy-3-methylbenzoate (9 g, $50 \mathrm{mmol}$ ) was dissolved in $50 \mathrm{~mL}$ of ethanol and stirred with heating to $60^{\circ} \mathrm{C}$ for 15 minutes; excess of hydrazine hydrate was added with small portions. After complete the addition the mixture left under reflux for $18 \mathrm{~h}$. On cooling a precipitate was filtered, washed with cold water and recrystallized from aqueous ethanol to afford white precipitate $7.1 \mathrm{~g}$, $86 \%$ yield, m.p.(191-193) ${ }^{\circ} \mathrm{C}$. IR $\left(\mathrm{KBr}, v_{\max } / \mathrm{cm}^{-1}\right)$ 3323, 3267, $3136\left(\mathrm{NH}_{2}, \mathrm{NH}\right.$ and $\left.\mathrm{OH}_{\text {phenol }}\right), 3049$, $3014\left(\mathrm{CH}_{\text {aromatic }}\right)$ 2972-2765 $\left(\mathrm{CH}_{\text {aliphatic }}\right), 1650(\mathrm{C}=\mathrm{O})$, 1583- $1433(\mathrm{C}=\mathrm{C}) .{ }^{1} \mathrm{H}$ NMR (400 MHz, DMSO-d $\left.)_{6}\right)$ $\delta$, ppm;2.22 (s, 3H, $\mathrm{CH}_{3}$ ), 4.69 (bs, 2H, $\mathrm{NH}_{2}$ ), 6.95 (t, $\left.1 \mathrm{H}, J 7.4, \mathrm{H}_{4}\right), 7.36\left(\mathrm{~d}, 1 \mathrm{H}, J\right.$ 7.34, $\left.\mathrm{H}_{5}\right), 7.44(\mathrm{~d}, 1 \mathrm{H}$, J 7.82, $\left.\mathrm{H}_{3}\right), 9.41$ (bs, $1 \mathrm{H}, \mathrm{NH}$ ).

\section{6-(5-thio-1,3,4-oxadiazol-2-yl)-2-methylphenol}

To a solution of hydrazide $(1.66 \mathrm{~g}, 10 \mathrm{mmol})$ and excess of carbon disulfide $(2.5-3 \mathrm{~mL})$ in absolute ethanol, potassium hydroxide $(0.62 \mathrm{~g}, 11 \mathrm{mmol})$ was added in one portion at ambient temperatures. The mixture was stirred and refluxed for $5 \mathrm{~h}$. The solvent was removed under vacuum. Distilled water $(25 \mathrm{~mL})$ was added to the residue and stirred for another 15 minutes. It was filtered and the filtrate acidified with $5 \%$ hydrochloric acid and finally re-filtered. The white precipitate was washed with water, recrystallized from ethanol to affords white crystal, yield $1.83 \mathrm{~g}$, (88 \%); m.p. (212-213) R C; IR (KBr, v $\left.{ }_{\max } / \mathrm{cm}^{-1}\right) 3365$ (NH) $3066\left(\mathrm{OH}_{\text {phenol }}\right), 2931,2765\left(\mathrm{CH}_{\text {aliphatic }}\right), 1606$ $(\mathrm{C}=\mathrm{N}), 1579-1469(\mathrm{C}=\mathrm{C}), 1122(\mathrm{C}=\mathrm{S}) ;{ }^{1} \mathrm{H}$ NMR $\left(400 \mathrm{MHz}, \mathrm{DMSO}-\mathrm{d}_{6}\right) \delta, \mathrm{ppm} ; 2.21\left(\mathrm{~s}, 3 \mathrm{H}, \mathrm{CH}_{3}\right.$ ), $6.92\left(\mathrm{t}, 1 \mathrm{H}, J 7.2, \mathrm{H}_{4}\right), 7.34\left(\mathrm{~d}, 1 \mathrm{H}, J \mathrm{~J} .3, \mathrm{H}_{3}\right), 7.45$ (d, $1 \mathrm{H}, J$ 7.8, $\mathrm{H}_{5}$ ), 9.16 (bs, $\left.1 \mathrm{H}, \mathrm{NH}\right) ;{ }^{13} \mathrm{C}$ APT $(100$ $\left.\mathrm{MHz}, \mathrm{DMSO}-\mathrm{d}_{6}\right)$ ä, ppm; $16.51\left(1 \mathrm{C}, \mathrm{CH}_{3}\right), 109.65$ $\left(1 \mathrm{C}, \mathrm{C}_{6}\right), 120.51\left(1 \mathrm{C}, \mathrm{C}_{4}\right), 126.35\left(1 \mathrm{C}, \mathrm{C}_{5}\right), 127.04$ $\left(1 \mathrm{C}, \mathrm{C}_{2}\left(, 135.11\left(1 \mathrm{C}, \mathrm{C}_{3}\right), 154.30\left(1 \mathrm{C}, \mathrm{C}_{1}(, 160.59\right.\right.\right.$ $\left(1 \mathrm{C}, \mathrm{C}_{7},(\mathrm{C}=\mathrm{N})\right), 177.24\left(1 \mathrm{C}, \mathrm{C}_{8},(\mathrm{C}=\mathrm{S})\right)$.

General method of Alkylation 6-(5-thio-1,3,4oxadiazol-2-yl)-2-methylphenol (3a-e)

Alkyl halide $(1 \mathrm{mmol})$ was added in small 
portions to a stirred suspension of 1,3,4-oxadiazole $(0.21 \mathrm{~g}, 1 \mathrm{mmol})$ in dry acetone and anhydrous potassium carbonate( $0.13 \mathrm{~g}, 1 \mathrm{mmol})$. The mixture was left to stand overnight with stirring at ambient temperature. The solvent was evaporated and the residue extracted with $25 \mathrm{~mL}$ chloroform. It was dried under anhydrous magnesium sulfate and recrystallized from suitable solvent.

\section{6-(5-(ethylthio)-1, 3, 4-oxadiazol-2-yl)-2- methylphenol(3a)}

The crude product was recrystallized from ethanol to give white crystal. Yeild $0.197 \mathrm{~g}$, (83\%); m.p. (74-76 RC); IR ( $\left.\mathrm{KBr}, v_{\max } / \mathrm{cm}^{-1}\right) 3172\left(\mathrm{OH}_{\text {phenol }}\right)$, $3030\left(\mathrm{CH}_{\text {aromatic }}\right), 2964-2864\left(\mathrm{CH}_{\text {aliphatic }}\right), 1610(\mathrm{C}=\mathrm{N})$, 1556-1425 (C=C); ${ }^{1} \mathrm{H}$ NMR (400 MHz, DMSO-d $)$ ), $\delta$, ppm; 1.44 (t, 3H, J 7.3, $\left.\mathrm{CH}_{2} \underline{\mathrm{CH}}_{3}\right), 2.25$ (s, 3H, $\mathrm{CH}_{3}$ ), 3.34 (s, 2H, CH $\mathrm{CH}_{2}, 6.96$ ( d, 1H, J 7.2, $\left.\mathrm{H}_{3}\right), 7.45$ (m, $\left.2 \mathrm{H}, \mathrm{H}_{4}, \mathrm{H}_{5}\right), 9.89$ (s, $\left.1 \mathrm{H}, \mathrm{OH}\right) ;{ }^{13} \mathrm{C}$ APT (100 MHz, DMSO- $\mathrm{d}_{6}$ ) $\delta$, ppm; 15.30 (1C, $\left.\mathrm{CH}_{2} \underline{\mathrm{CH}}_{3}\right), 16.20$ (1C, $\left.\mathrm{CH}_{3}\right), 27.25\left(1 \mathrm{C}, \mathrm{CH}_{2}\right), 108.25\left(1 \mathrm{C}, \mathrm{C}_{6}\right), 120.34(1 \mathrm{C}$, $\left.\mathrm{C}_{4}\right), 125.21\left(1 \mathrm{C}, \mathrm{C}_{5}\right), 126.44\left(1 \mathrm{C}, \mathrm{C}_{2}\right), 134.95(1 \mathrm{C}$, $\left.\mathrm{C}_{3}\right), 154.78\left(1 \mathrm{C}, \mathrm{C}_{1}\right), 163.73\left(1 \mathrm{C}, \mathrm{C}_{8}\right), 165.28(1 \mathrm{C}$, $\mathrm{C}_{7}$ ).

\section{6-(5-(((benzoimidazol-2-yl)methyl)thio)-1,3,4- oxadiazol-2-yl)-2-methylphenol}

The solid crude was recrystallized from (1:1) ethyl acetate: methanol to give light brownish crystal. Yeild0.26 g, (77\%); m.p.(173-175)C ; IR $\left(\mathrm{KBr}, v_{\max } / \mathrm{cm}^{-1}\right) 3174(\mathrm{NH}), 3080\left(\mathrm{OH}_{\text {phenol }}\right), 3024$ $\left(\mathrm{CH}_{\text {aromatic }}\right), 2989-2924\left(\mathrm{CH}_{\text {aliphatic }}\right), 1618(\mathrm{C}=\mathrm{N})$, 1556-1439 (C=C); ${ }^{1} \mathrm{H}$ NMR (400 MHz, DMSO-d d $_{6}$ $\delta$, ppm; $2.23\left(\mathrm{~s}, 3 \mathrm{H}, \mathrm{CH}_{3}\right), 4.80\left(\mathrm{~s}, 2 \mathrm{H}, \mathrm{CH}_{2}\right), 6.93$ $\left(\mathrm{t}, 1 \mathrm{H}, J 7.46, \mathrm{H}_{4}\right), 7.18\left(\mathrm{~m}, 2 \mathrm{H}, \mathrm{H}_{13}\right), 7.37(\mathrm{~d}, 1 \mathrm{H}$, J 7.1, $\left.\mathrm{H}_{3}\right), 7.52\left(\mathrm{~m}, 3 \mathrm{H}, \mathrm{H}_{5}, \mathrm{H}_{12}\right), 9.85(\mathrm{~s}, 1 \mathrm{H}, \mathrm{OH})$, 12.67 (bs, $1 \mathrm{H}, \mathrm{NH}) ;{ }^{13} \mathrm{C}$ APT (100 MHz, DMSO-d 6 ) $\delta$, ppm;16.17 (1C, $\left.\mathrm{CH}_{3}\right), 30.16\left(1 \mathrm{C}, \mathrm{CH}_{2}\right), 108.11$ $\left(1 \mathrm{C}, \mathrm{C}_{6}\right), 120.42\left(1 \mathrm{C}, \mathrm{C}_{4}\right), 122.61\left(2 \mathrm{C}, \mathrm{C}_{12}, \mathrm{C}_{13}\right)$, $125.37\left(1 \mathrm{C}, \mathrm{C}_{5}\right), 126.54\left(1 \mathrm{C}, \mathrm{C}_{2}\right), 135.16\left(1 \mathrm{C}, \mathrm{C}_{3}\right)$, $149.85\left(2 \mathrm{C}, \mathrm{C}_{10}, \mathrm{C}_{11}\right), 154.74\left(1 \mathrm{C}, \mathrm{C}_{1}\right), 162.69(1 \mathrm{C}$, $\left.\mathrm{C}_{8}\right), 165.67\left(1 \mathrm{C}, \mathrm{C}_{7}\right)$

\section{6-(5-((4-bromobenzoyl)methylthio)-1,3,4- oxadiazol-2-yl)-2-methylphenol}

The crude product was recrystallized from acetonitrile to give white precipitate. Yield $0.35 \mathrm{~g}$, 86\% m.p.(164-166) C, IR (KBr, $\left.v_{\max } / \mathrm{cm}^{-1}\right) 3192$ $\left(\mathrm{OH}_{\text {phenol }}\right), 3033\left(\mathrm{CH}_{\text {aromatic }}\right), 2960-2924\left(\mathrm{CH}_{\text {aliphatic }}\right)$,
$1678(\mathrm{C}=\mathrm{O}), 1614(\mathrm{C}=\mathrm{N}), 1591-1477(\mathrm{C}=\mathrm{C}) ;{ }^{1} \mathrm{H}$ NMR (400 MHz, DMSO-d $\left.)_{6}\right) \delta, p p m ; 2.25$ (s, 3H, $\left.\mathrm{CH}_{3}\right), 5.16\left(\mathrm{~s}, 2 \mathrm{H}, \mathrm{CH}_{2}\right), 6.95\left(\mathrm{t}, 1 \mathrm{H}, J 7.3, \mathrm{H}_{4}\right), 7.39$ $\left(\mathrm{d}, 1 \mathrm{H}, J 7.0, \mathrm{H}_{3}\right), 7.55\left(\mathrm{~d}, 1 \mathrm{H}, J 7.3, \mathrm{H}_{5}\right), 7.81(\mathrm{~d}$, $\left.2 \mathrm{H}, J 8.1, \mathrm{H}_{13}\right), 8.02\left(\mathrm{~d}, J 8.3,2 \mathrm{H}, \mathrm{H}_{12}\right), 9.81(\mathrm{~s}, 1 \mathrm{H}$, $\mathrm{OH}) ;{ }^{13} \mathrm{C}$ APT (100 MHz, DMSO-d 6 ) $\delta$, ppm; 16.19 $\left(1 \mathrm{C}, \mathrm{CH}_{3}\right), 40.83\left(1 \mathrm{C}, \mathrm{CH}_{2}\right), 108.13\left(1 \mathrm{C}, \mathrm{C}_{6}\right), 120$ $\left(1 \mathrm{C}, \mathrm{C}_{4}\right), 125.33\left(1 \mathrm{C}, \mathrm{C}_{5}\right), 126.55\left(1 \mathrm{C}, \mathrm{C}_{2}\right), 128.73$ $\left(1 \mathrm{C}, \mathrm{C}_{14}\right), 130.94\left(2 \mathrm{C}, \mathrm{C}_{12}\right), 132.50\left(2 \mathrm{C}, \mathrm{C}_{13}\right), 134.44$ $\left(1 \mathrm{C}, \mathrm{C}_{11}\right), 135.16\left(1 \mathrm{C}, \mathrm{C}_{3}\right), 154.73\left(1 \mathrm{C}, \mathrm{C}_{1}\right), 163.20$ $\left(1 \mathrm{C}, \mathrm{C}_{8},(\mathrm{C}=\mathrm{N})\right), 165.38\left(1 \mathrm{C}, \mathrm{C}_{7},(\mathrm{C}=\mathrm{N})\right), 192.44(1 \mathrm{C}$, $\left.\mathrm{C}_{10},(\mathrm{C}=\mathrm{O})\right)$.

\section{6-(5-((ethoxyformyl)methylthio)-1,3,4-oxadiazol-} 2-yl)-2-methylphenol

Recrystallization of the crude product from chloroform to give pale yellow precipitate. Yield 0.22 g, 74\% m.p.(71-73) C, IR ( $\left.\mathrm{KBr}, v_{\max } / \mathrm{cm}^{-1}\right) 3207$ $\left(\mathrm{OH}_{\text {phenol }}\right), 3037\left(\mathrm{CH}_{\text {aromatic }}\right), 2983-2931\left(\mathrm{CH}_{\text {aliphatic }}\right)$, $1728(\mathrm{C}=\mathrm{O}), 1606(\mathrm{C}=\mathrm{N}), 1556-1481(\mathrm{C}=\mathrm{C}) ;{ }^{1} \mathrm{H}$ NMR $\left(300 \mathrm{MHz}, \mathrm{DMSO}-\mathrm{d}_{6}\right) \delta$, ppm; $1.20\left(\mathrm{t}, 3 \mathrm{H}, J 6.96, \mathrm{H}_{12}\right)$, $2.26\left(\mathrm{~s}, 3 \mathrm{H}, \mathrm{CH}_{3}\right), 4.16\left(\mathrm{q}, 2 \mathrm{H}, J\right.$ 7.16, $\left.\mathrm{H}_{11}\right), 4.32$ $\left(\mathrm{s}, 2 \mathrm{H}, \mathrm{SCH}_{2}, \mathrm{H}_{9}\right), 6.99$ (t, $\left.1 \mathrm{H}, J 7.72, \mathrm{H}_{4}\right), 7.41$ (d, $1 \mathrm{H}, J$ 7.35, $\left.\mathrm{H}_{3}\right), 7.59\left(\mathrm{~d}, 1 \mathrm{H}, J 7.2, \mathrm{H}_{5}\right), 9.82(\mathrm{~s}, 1 \mathrm{H}$, $\mathrm{OH}) ;{ }^{13} \mathrm{C}$ NMR $(75 \mathrm{MHz}$, DMSO-d $) \delta$, ppm; 13.93 $\left(1 \mathrm{C}, \mathrm{C}_{12}\right), 15.74\left(1 \mathrm{C}, \mathrm{CH}_{3}\right), 33.87\left(1 \mathrm{C}, \mathrm{C}_{9}\right), 61.63(1 \mathrm{C}$, $\left.\mathrm{C}_{11}\right), 107.72\left(1 \mathrm{C}, \mathrm{C}_{6}\right), 119.95\left(1 \mathrm{C}, \mathrm{C}_{4}\right), 124.87(1 \mathrm{C}$, $\left.\mathrm{C}_{5}\right), 126.08\left(1 \mathrm{C}, \mathrm{C}_{2}\right), 134.65\left(1 \mathrm{C}, \mathrm{C}_{3}\right), 154.28(1 \mathrm{C}$, $\left.\mathrm{C}_{1}\right), 162.44\left(1 \mathrm{C}, \mathrm{C}_{8},(\mathrm{C}=\mathrm{N})\right), 164.94\left(1 \mathrm{C}, \mathrm{C}_{7},(\mathrm{C}=\mathrm{N})\right)$, $167.62\left(1 \mathrm{C}, \mathrm{C}_{10},(\mathrm{C}=\mathrm{O})\right)$.

\section{6-(5-(benzylthio)-1,3,4-oxadiazol-2-yl)-2- methylphenol}

The desired product (3e) was purified by flash column chromatography using hexane: ethyl acetate $(6: 1)$ as eluent to give white precipitate. Yield 0.2g, 67\%, m.p.(100-103) C, IR (KBr, v max $^{\left./ \mathrm{cm}^{-1}\right)} 3153$ $\left(\mathrm{OH}_{\text {phenol }}\right), 3041\left(\mathrm{CH}_{\text {aromatic }}\right), 2924-2860\left(\mathrm{CH}_{\text {aliphatic }}\right)$, $1606(\mathrm{C}=\mathrm{N}), 1556-1414(\mathrm{C}=\mathrm{C}) ;{ }^{1} \mathrm{H}$ NMR $(300 \mathrm{MHz}$, DMSO-d d $\left._{6}\right) \delta$, ppm; 2.26 (s, 3H, $\mathrm{CH}_{3}$ ), 4.60 (s, 2H, $\left.\mathrm{SCH}_{2}\right), 6.97$ (td, 1H, J 7.6, 3.2, $\left.\mathrm{H}_{13}\right), 7.29-7.51(\mathrm{~m}$, $6 \mathrm{H}, \mathrm{H}_{3}, \mathrm{H}_{4}, \mathrm{H}_{11}, \mathrm{H}_{12}$ ), 7.58 (d, 1 H, J 7.9, $\mathrm{H}_{5}$ ), 9.85 (s, $1 \mathrm{H}, \mathrm{OH}) ;{ }^{13} \mathrm{C}$ NMR $\left(75 \mathrm{MHz}\right.$, DMSO-d $\left.{ }_{6}\right) \delta$, ppm; 15.71 $\left(1 \mathrm{C}, \mathrm{CH}_{3}\right), 35.92\left(1 \mathrm{C}, \mathrm{C}_{9}\right), 107.68\left(1 \mathrm{C}, \mathrm{C}_{6}\right), 119.91$ $\left(1 \mathrm{C}, \mathrm{C}_{4}\right), 124.81\left(1 \mathrm{C}, \mathrm{C}_{5}\right), 125.99\left(1 \mathrm{C}, \mathrm{C}_{2}\right), 127.79$ $\left(1 \mathrm{C}, \mathrm{C}_{13}\right), 128.57\left(2 \mathrm{C}, \mathrm{C}_{11}\right), 129.03\left(2 \mathrm{C}, \mathrm{C}_{12}\right), 134.57$ $\left(1 \mathrm{C}, \mathrm{C}_{3}\right), 156.42\left(1 \mathrm{C}, \mathrm{C}_{10}\right), 154.31\left(1 \mathrm{C}, \mathrm{C}_{1}\right), 162.74$ $\left(1 \mathrm{C}, \mathrm{C}_{8},(\mathrm{C}=\mathrm{N})\right), 164.96\left(1 \mathrm{C}, \mathrm{C}_{7},(\mathrm{C}=\mathrm{N})\right)$. 
General synthesis of N'(substitutedbenzylidene)2hydroxy-3-methylbenzohydrazide ( hydrazone) (4a-e)

To a warm stirred solution of arylaldehyde (3 $\mathrm{mmol}$ ) in $20 \mathrm{~mL}$ absolute ethanol, 2-hydroxy-3methylbenzohydrazide $(0.48 \mathrm{~g}, 3 \mathrm{mmol})$ was added in small portions, and refluxed for $7 \mathrm{~h}$, upon cooling; the mixture was stored overnight in a refrigerator at $5^{\circ} \mathrm{C}$. The precipitate was washed with cold ethanol and recrystallized from suitable solvent.

\section{N'(4-methylbenzylidene)2-hydroxy-3- methylbenzohydrazide}

The crude precipitate (4a) was recrystallized from ethanol to give white crystals. Yield $0.52 \mathrm{~g}$, $67 \%$, m.p.(173-174)C, IR (KBr, v $\left.v_{\max } / \mathrm{cm}^{-1}\right) 3240(\mathrm{NH}$ and $\left.\mathrm{OH}_{\text {phenol }}\right), 3087-3028\left(\mathrm{CH}_{\text {aromatic }}\right), 2954-2910$ $\left(\mathrm{CH}_{\text {aliphatic }}\right), 1603\left(\mathrm{C}=\mathrm{O}_{\text {amide }}\right)$ and $(\mathrm{C}=\mathrm{N}), 1572-1446$ $(\mathrm{C}=\mathrm{C}) ;{ }^{1} \mathrm{H}$ NMR (300 MHz, DMSO-d $\left.\mathrm{d}_{6}\right) \delta, \mathrm{ppm} ; 2.19$ $\left(\mathrm{s}, 3 \mathrm{H}, \mathrm{C}_{2}-\mathrm{CH}_{3}\right), 2.36\left(\mathrm{~s}, 3 \mathrm{H}, \mathrm{C}_{12}-\mathrm{CH}_{3}\right), 6.87(\mathrm{t}, 1 \mathrm{H}, J$ 7.6, $\left.\mathrm{H}_{4}\right), 7.3\left(\mathrm{~d}, 2 \mathrm{H}, J 7.9, \mathrm{H}_{11}\right), 7.37(\mathrm{~d}, 1 \mathrm{H}, J$ 7.3, $\left.\mathrm{H}_{3}\right), 7.65\left(\mathrm{~d}, 2 \mathrm{H}, J \mathrm{~J} .9, \mathrm{H}_{10}\right), 7.81\left(\mathrm{~d}, 1 \mathrm{H}, J 7.9, \mathrm{H}_{5}\right)$, $8.48\left(\mathrm{~s}, 1 \mathrm{H}, \mathrm{H}_{8},(\mathrm{CH}=\mathrm{N})\right), 11.99(\mathrm{~s}, 1 \mathrm{H}, \mathrm{NH}), 12.67$ (s, $1 \mathrm{H}, \mathrm{OH}) ;{ }^{13} \mathrm{C}$ NMR (75 MHz, DMSO-d ${ }_{6}$ ) $\delta$, ppm; $15.46\left(1 \mathrm{C}, \mathrm{C}_{2}-\mathrm{CH}_{3}\right), 21.02\left(1 \mathrm{C}, \mathrm{C}_{12}-\mathrm{CH}_{3}\right), 112.73(1 \mathrm{C}$, $\left.\mathrm{C}_{6}\right), 117.96\left(1 \mathrm{C}, \mathrm{C}_{4}\right), 124.69\left(1 \mathrm{C}, \mathrm{C}_{5}\right), 126.17(1 \mathrm{C}$, $\left.\mathrm{C}_{2}\right), 127.27\left(2 \mathrm{C}, \mathrm{C}_{10}\right), 129.48\left(2 \mathrm{C}, \mathrm{C}_{11}\right), 131.21(1 \mathrm{C}$, $\left.\mathrm{C}_{9}\right), 135.01\left(1 \mathrm{C}, \mathrm{C}_{3}\right), 140.33\left(1 \mathrm{C}, \mathrm{C}_{12}\right), 149.44(1 \mathrm{C}$, $\left.\mathrm{C}_{8}\right), 159.43\left(1 \mathrm{C}, \mathrm{C}_{1}\right), 166.61\left(1 \mathrm{C}, \mathrm{C}_{7}\right)$.

\section{N'(4-hydroxybenzylidene)2- hydroxy-3- methylbenzohydrazide}

Recrystallization of the crude product(4b) from methanole to give white precipitate. Yield 0.6 g, 78\%,m.p.(240-242) C, IR (KBr, v $\left.v_{\max } / \mathrm{cm}^{-1}\right) 3278$ $\mathrm{NH}, 3205\left(\mathrm{OH}_{\text {phenol }}\right), 3080-3020\left(\mathrm{CH}_{\text {aromatic }}\right)$, 2985$2912\left(\mathrm{CH}_{\text {aliphatic }}\right), 1603(\mathrm{C}=\mathrm{O})$ and $(\mathrm{C}=\mathrm{N}), 1554-1435$ $(\mathrm{C}=\mathrm{C}) ;{ }^{1} \mathrm{H}$ NMR (300 MHz, DMSO-d $\left.\mathrm{d}_{6}\right) \delta$, ppm; 2.19 $\left(\mathrm{s}, 3 \mathrm{H}, \mathrm{CH}_{3}\right), 6.86\left(\mathrm{~m}, 3 \mathrm{H}, \mathrm{H}_{4}, 2 \times \mathrm{H}_{11}\right), 7.36(\mathrm{~d}, 1 \mathrm{H}$, J 6, $\left.\mathrm{H}_{3}\right), 7.6\left(\mathrm{~d}, 2 \mathrm{H}, J\right.$ 8.3, $\left.\mathrm{H}_{10}\right), 7.8\left(\mathrm{~d}, 1 \mathrm{H}, \mathrm{J} 2.24, \mathrm{H}_{5}\right)$, 8.41(s,1H, $\left.\mathrm{H}_{8},(\mathrm{CH}=\mathrm{N})\right), 10.02\left(\mathrm{bs}, 1 \mathrm{H}, \mathrm{C}_{12}-\mathrm{OH}\right), 11.86$ (bs, $1 \mathrm{H}, \mathrm{NH}$ ), 12.80 (bs, $\left.1 \mathrm{H}, \mathrm{C}_{1}-\mathrm{OH}\right) ;{ }^{13} \mathrm{C}$ APT (75 $\left.\mathrm{MHz}, \mathrm{DMSO}-\mathrm{d}_{6}\right) \delta$, ppm; $15.47\left(1 \mathrm{C}, \mathrm{CH}_{3}\right), 112.76$ (1C, $\left.\mathrm{C}_{6}\right), 115.75\left(2 \mathrm{C}, \mathrm{C}_{11}\right), 117.89\left(1 \mathrm{C}, \mathrm{C}_{4}\right), 124.54(1 \mathrm{C}$, $\left.\mathrm{C}_{5}\right), 124.88\left(1 \mathrm{C}, \mathrm{C}_{2}\right), 126.15\left(1 \mathrm{C}, \mathrm{C}_{9}\right), 129.12\left(2 \mathrm{C}, \mathrm{C}_{10}\right)$, $134.87\left(1 \mathrm{C}, \mathrm{C}_{3}\right), 149.73\left(1 \mathrm{C}, \mathrm{C}_{8}(\mathrm{C}=\mathrm{N})\right), 159.46(1 \mathrm{C}$, $\left.\mathrm{C}_{1}\right), 159.73\left(1 \mathrm{C}, \mathrm{C}_{12}\right), 166.38\left(1 \mathrm{C}, \mathrm{C}_{7},(\mathrm{C}=\mathrm{O})\right)$.
N'(4-hydroxy-3-methoxybenzylidene)2-hydroxy3-methylbenzohydrazide

Recrystallization of the crude product (4c)from methanole to give pale yellow precipitate. Yield 0.72 g, 83\%, m.p.(203-206) C, IR (KBr, v max $^{\prime}$ $\left.\mathrm{cm}^{-1}\right) 3311 \mathrm{NH}, 3194\left(\mathrm{OH}_{\text {phenol }}\right), 3060\left(\mathrm{CH}_{\text {aromatic }}\right)$, 2962-2856 $\left(\mathrm{CH}_{\text {aliphatic }}\right), 1633(\mathrm{C}=\mathrm{O}), 1603(\mathrm{C}=\mathrm{N})$, 1550-1431 ( $\mathrm{C}=\mathrm{C}) ;{ }^{1} \mathrm{H}$ NMR (400 MHz, DMSO-d $\left.\mathrm{d}_{6}\right)$ $\delta$, ppm;2.23 (s, 3H, $\left.\mathrm{CH}_{3}\right), 3.88$ (s, 3H, O- $\left.\mathrm{CH}_{3}\right), 6.89$ $\left(\mathrm{m}, 2 \mathrm{H}, \mathrm{H}_{4}, \mathrm{H}_{13}\right), 7.16\left(\mathrm{dd}, 1 \mathrm{H}, \mathrm{J} 8, \mathrm{H}_{14}\right), 7.39$ (m, $\left.2 \mathrm{H}, \mathrm{H}_{10}, \mathrm{H}_{3}\right), 7.83\left(\mathrm{~d}, 1 \mathrm{H}, J\right.$ 7.9, $\left.\mathrm{H}_{5}\right), 8.44(\mathrm{~s}, 1 \mathrm{H}$, $\left.\mathrm{H}_{8}\right), 9.66\left(\mathrm{~s}, 1 \mathrm{H}, \mathrm{OH}_{\text {vanillin }}\right), 11.90(\mathrm{~s}, 1 \mathrm{H}, \mathrm{NH}), 12.80$ $\left(\mathrm{s}, 1 \mathrm{H}, \mathrm{OH}_{\text {phenol }}\right) ;{ }^{13} \mathrm{C}$ APT $\left(100 \mathrm{MHz}\right.$, DMSO- $\left.\mathrm{d}_{6}\right)$ $\delta$, ppm; $15.96\left(1 \mathrm{C}, \mathrm{CH}_{3}\right), 56.03\left(1 \mathrm{C}, \mathrm{O}-\mathrm{CH}_{3}\right), 109.47$ $\left(1 \mathrm{C}, \mathrm{C}_{10}\right), 113.31\left(1 \mathrm{C}, \mathrm{C}_{6}\right), 115.94\left(1 \mathrm{C}, \mathrm{C}_{13}\right), 118.39$ $\left(1 \mathrm{C}, \mathrm{C}_{14}\right), 123.11\left(1 \mathrm{C}, \mathrm{C}_{4}\right), 125.12\left(1 \mathrm{C}, \mathrm{C}_{5}\right), 125.81$ $\left(1 \mathrm{C}, \mathrm{C}_{9}\right), 126.66\left(1 \mathrm{C}, \mathrm{C}_{2}\right), 135.38\left(1 \mathrm{C}, \mathrm{C}_{3}\right), 148.57(1 \mathrm{C}$, $\left.\mathrm{C}_{11}\right), 149.86\left(1 \mathrm{C}, \mathrm{C}_{12}\right), 150.45\left(1 \mathrm{C}, \mathrm{C}_{8}\right), 159.96$ (1C, $\left.C_{1}\right), 166.89\left(1 \mathrm{C}, C_{7},(C=O)\right)$.

\section{N'(4-hydroxy-3,5-dimethoxybenzylidene)2-} hydroxy-3-methylbenzohydrazide

Recrystallization of the crude product (4d) from methanol to give pale brown precipitate. Yield $0.77 \mathrm{~g}, 81 \%$,m.p.(210-213) C, IR $\left(\mathrm{KBr}, v_{\max } / \mathrm{cm}^{-1}\right)$ $3317\left(\mathrm{NH}\right.$ and $\left.\mathrm{OH}_{\text {phenol }}\right), 3086-3022\left(\mathrm{CH}_{\text {aromatic }}\right), 2951-$ $2844\left(\mathrm{CH}_{\text {aliphatic }}\right), 1630(\mathrm{C}=\mathrm{O})$ and $(\mathrm{C}=\mathrm{N}), 1587-1425$ $(\mathrm{C}=\mathrm{C}) ;{ }^{1} \mathrm{H}$ NMR (300 MHz, DMSO-d $\left.{ }_{6}\right) \delta, p p m ; 2.2$ (s, $3 \mathrm{H}, \mathrm{CH}_{3}$ ), 3.83 (s, $\left.6 \mathrm{H}, 2 \times \mathrm{OCH}_{3}\right), 6.87(\mathrm{t}, 1 \mathrm{H}, J$ 7.6, $\left.\mathrm{H}_{4}\right), 7.02\left(\mathrm{~s}, 2 \mathrm{H}, \mathrm{H}_{10}\right), 7.37\left(\mathrm{~d}, 1 \mathrm{H}, J 7.3, \mathrm{H}_{3}\right), 7.8$ (s, $\left.1 \mathrm{H}, J 7.9, \mathrm{H}_{5}\right), 8.39\left(\mathrm{~s}, 1 \mathrm{H}, \mathrm{H}_{8(\mathrm{CH}=\mathrm{N})}\right), 9.01(\mathrm{~s}, 1 \mathrm{H}$, $\left.\mathrm{C}_{12}-\mathrm{OH}\right), 11.93(\mathrm{~s}, 1 \mathrm{H}, \mathrm{NH}), 12.74\left(\mathrm{~s}, 1 \mathrm{H}, \mathrm{C}_{1}-\mathrm{OH}\right) ;{ }^{13} \mathrm{C}$ NMR $\left(75 \mathrm{MHz}, \mathrm{DMSO}-\mathrm{d}_{6}\right) \delta$, ppm; $15.48\left(1 \mathrm{C}, \mathrm{CH}_{3}\right)$, $56.02\left(2 \mathrm{C}, 2 \times \mathrm{OCH}_{3}\right), 104.83\left(2 \mathrm{C}, \mathrm{C}_{10}\right), 112.82(1 \mathrm{C}$, $\left.\mathrm{C}_{6}\right), 117.92\left(1 \mathrm{C}, \mathrm{C}_{4}\right), 124.11\left(1 \mathrm{C}, \mathrm{C}_{9}\right), 124.67\left(1 \mathrm{C}, \mathrm{C}_{5}\right)$, $126.16\left(1 \mathrm{C}, \mathrm{C}_{2}\right), 134.91\left(1 \mathrm{C}, \mathrm{C}_{3}\right), 138.29\left(1 \mathrm{C}, \mathrm{C}_{12}\right)$, $148.12\left(1 \mathrm{C}, \mathrm{C}_{8}(\mathrm{C}=\mathrm{N})\right), 150.02\left(2 \mathrm{C}, \mathrm{C}_{11}\right), 159.42(1 \mathrm{C}$, $\left.C_{1}\right), 166.39\left(1 \mathrm{C}, C_{7}(\mathrm{C}=\mathrm{O})\right)$.

N'(2-hydroxy-3,5-di-tertbutylbenzylidene)2hydroxy-3-methylbenzohydrazide

Recrystallization of the crude product (4e) of from ethanol and water to give white precipitate. Yield 0.85 g, 77\%, m.p.(205-208) C, IR $\left(\mathrm{KBr}, v_{\max } / \mathrm{cm}^{-1}\right) ; 3217 \mathrm{NH}, 3174\left(\mathrm{OH}_{\text {phenol }}\right), 3049$ $\left(\mathrm{CH}_{\text {aromatic }}\right), 2962-2864\left(\mathrm{CH}_{\text {aliphatic }}\right), 1633(\mathrm{C}=\mathrm{O})$ and $(\mathrm{C}=\mathrm{N}), 1587-1435(\mathrm{C}=\mathrm{C}) ;{ }^{1} \mathrm{H}$ NMR $(300 \mathrm{MHz}$, 
DMSO-d $\left.{ }_{6}\right) \delta$, ppm;1.30-1.42 (s, 18H, $\mathrm{CH}_{3}$ ), 2.21 (s, $\left.3 \mathrm{H}, \mathrm{CH}_{3}\right), 6.91\left(\mathrm{~m}, 1 \mathrm{H}, \mathrm{H}_{4}\right), 7.26\left(\mathrm{~d}, 1 \mathrm{H}, \mathrm{J} 2.3, \mathrm{H}_{12}\right)$, $7.34\left(\mathrm{~d}, 1 \mathrm{H}, \mathrm{J} 2.1, \mathrm{H}_{14}\right), 7.41\left(\mathrm{~d}, 1 \mathrm{H}, J 6.8, \mathrm{H}_{3}\right), 7.8$ (d, $\left.1 \mathrm{H}, J 7.9, \mathrm{H}_{5}\right), 8.65\left(\mathrm{~s}, 1 \mathrm{H}, \mathrm{H}_{8},(\mathrm{C}=\mathrm{N})\right), 12.23$ (bs, $1 \mathrm{H}, \mathrm{NH}), 12.43$ (bs, $2 \mathrm{H}, 2 \mathrm{OH}) ;{ }^{13} \mathrm{C}$ NMR $(75 \mathrm{MHz}$, DMSO-d $\left.)_{6}\right) \delta$, ppm; 15.57(1C, $\left.\mathrm{CH}_{3}\right), 29.25\left(3 \mathrm{C}, \mathrm{C}_{16}\right.$, $\left.\mathrm{C}\left(\underline{\mathrm{CH}}_{3}\right)_{3}\right), 31.25\left(3 \mathrm{C}, \mathrm{C}_{18}, \mathrm{C}\left(\underline{\mathrm{CH}}_{3}\right)_{3}\right), 33.84\left(1 \mathrm{C}, \mathrm{C}_{17}\right.$, $\left.\underline{\mathrm{C}}\left(\mathrm{CH}_{3}\right)_{3}\right), 34.62\left(1 \mathrm{C}, \mathrm{C}_{15}, \underline{\mathrm{C}}\left(\mathrm{CH}_{3}\right)_{3}\right), 116.99\left(1 \mathrm{C}, \mathrm{C}_{6}\right)$, $117.74\left(1 \mathrm{C}, \mathrm{C}_{9}\right), 119.12\left(1 \mathrm{C}, \mathrm{C}_{4}\right), 120.30\left(1 \mathrm{C}, \mathrm{C}_{14}\right)$, $124.97\left(1 \mathrm{C}, \mathrm{C}_{12}\right), 125.65\left(1 \mathrm{C}, \mathrm{C}_{5}\right), 125.81\left(1 \mathrm{C}, \mathrm{C}_{2}\right)$, $126.19\left(1 \mathrm{C}, \mathrm{C}_{3}\right), 135.64\left(1 \mathrm{C}, \mathrm{C}_{11}\right), 140.38\left(1 \mathrm{C}, \mathrm{C}_{13}\right)$, $152.11\left(1 \mathrm{C}, \mathrm{C}_{8},(\mathrm{C}=\mathrm{N})\right), 154.83\left(1 \mathrm{C}, \mathrm{C}_{10}\right), 159.62(1 \mathrm{C}$, $\left.\mathrm{C}_{1}\right), 166.48\left(1 \mathrm{C}, \mathrm{C}_{7},(\mathrm{C}=\mathrm{O})\right)$.

General synthesis of 6-(5-(Aryl)-1,3,4-oxadiazol2-yl)-2-methylphenol (5a-i)

Method A

To a suspension of N'(substituted benzylidene)2- hydroxy-3-methylbenzohydrazide (1 $\mathrm{mmol})$ in $5 \mathrm{~mL}$ glacial acetic acid and $(2 \mathrm{mmol})$ of anhydrous sodium acetate, bromine solution (1 $\mathrm{mmol}$ ) in $3 \mathrm{~mL}$ glacial acetic acid was added dropwise at ambient temperatures. The mixture was refluxed for $4 \mathrm{~h}$. After cooling the mixture was poured into $100 \mathrm{~mL}$ ice water and stirred for another 30 minutes. The precipitate was collected, washed with water and dried. The crude product was purified either by flash column chromatography using suitable eluent or by recrystallization from suitable solvent.

\section{6-(5-(4-methylphenyl)-1,3,4-oxadiazol-2-yl)-2- methylphenol}

The product $(5 \mathrm{a})$ was purified by flash column chromatography using hexane-ethyl acetate (3:1) as eluentto give off-white precipitate.Yield 0.18 g, 73\%, m.p.(158-160) C, IR (KBr, v $\left.v_{\max } / \mathrm{cm}^{-1}\right) 3128$ $\left(\mathrm{OH}_{\text {phenol }}\right), 3026\left(\mathrm{CH}_{\text {aromatic }}\right), 2962-2848\left(\mathrm{CH}_{\text {aliphatic }}\right)$, $1610(\mathrm{C}=\mathrm{N}), 1543-1417(\mathrm{C}=\mathrm{C}) ;{ }^{1} \mathrm{H}$ NMR $(300 \mathrm{MHz}$, DMSO-d $\left.\mathrm{d}_{6}\right) \delta$, ppm; 2.03 (s, 3H, $\left.\mathrm{C}_{2}-\mathrm{CH}_{3}\right), 2.2(\mathrm{~s}, 3 \mathrm{H}$, $\left.\mathrm{C}_{12}-\mathrm{CH}_{3}\right), 6.7\left(\mathrm{t}, 1 \mathrm{H}, J 7.6, \mathrm{H}_{4}\right), 7.13(\mathrm{~d}, 2 \mathrm{H}, J 7.9$, $\left.\mathrm{H}_{11}\right), 7.21\left(\mathrm{~d}, 1 \mathrm{H}, J\right.$ J.3, $\left.\mathrm{H}_{3}\right), 7.49\left(\mathrm{~d}, 2 \mathrm{H}, J\right.$ 7.9, $\left.\mathrm{H}_{10}\right)$, 7.64(d,1H, J7.9, $\left.\mathrm{H}_{5}\right), 11.83$ (s, $\left.1 \mathrm{H}, \mathrm{OH}\right) ;{ }^{13} \mathrm{C} \mathrm{NMR}(75$ $\left.\mathrm{MHz}, \mathrm{DMSO}-\mathrm{d}_{6}\right) \delta$, ppm; 15.26(1C, $\left.\mathrm{C}_{2}-\mathrm{CH}_{3}\right), 20.83$ $\left(1 \mathrm{C}, \mathrm{C}_{12}-\mathrm{CH}_{3}\right), 112.53\left(1 \mathrm{C}, \mathrm{C}_{6}\right), 117.76\left(1 \mathrm{C}, \mathrm{C}_{4}\right)$, $124.50\left(1 \mathrm{C}, \mathrm{C}_{5}\right), 125.96\left(1 \mathrm{C}, \mathrm{C}_{2}\right), 127.06\left(2 \mathrm{C}, \mathrm{C}_{11}\right)$, , $129.28\left(2 \mathrm{C}, \mathrm{C}_{10}\right), 131.00\left(1 \mathrm{C}, \mathrm{C}_{12}\right), 134.81\left(1 \mathrm{C}, \mathrm{C}_{3}\right)$, $140.13\left(1 \mathrm{C}, \mathrm{C}_{9}\right), 159.23\left(1 \mathrm{C}, \mathrm{C}_{1}\right), 163.59\left(1 \mathrm{C}, \mathrm{C}_{7}\right)$, $165.39\left(1 \mathrm{C}, \mathrm{C}_{8}\right)$. 6-(5-(4-hydroxylphenyl)-1,3,4-oxadiazol-2-yl)-2methylphenol

The crude product (5b) was recrystallized from methanole to give pale beige precipitate. Yield $0.2 \mathrm{~g}, 75 \%$, m.p.(224-227) C, IR $\left(\mathrm{KBr}, v_{\max } / \mathrm{cm}^{-1}\right)$ $3464(\mathrm{OH}), 3150\left(\mathrm{OH}_{\text {phenol }}\right), 3078\left(\mathrm{CH}_{\text {aromatic }}\right), 2978$ $2924\left(\mathrm{CH}_{\text {aliphatic }}\right), 1622(\mathrm{C}=\mathrm{N}), 1599-1402(\mathrm{C}=\mathrm{C}) ;{ }^{1} \mathrm{H}$ NMR (300 MHz, DMSO-d ${ }_{6}$ ) $\delta, p p m ; 2.18$ (s, 3H, $\left.\mathrm{CH}_{3}\right), 6.85\left(\mathrm{~m}, 3 \mathrm{H}, \mathrm{H}_{4}, 2 \times \mathrm{H}_{11}\right), 7.35\left(\mathrm{~d}, 1 \mathrm{H}, \mathrm{J} 6, \mathrm{H}_{3}\right)$, $7.59\left(\mathrm{~d}, 2 \mathrm{H}, \mathrm{J} 8.3, \mathrm{H}_{10}\right), 7.79\left(\mathrm{~d}, 1 \mathrm{H}, J\right.$ 6.6, $\left.\mathrm{H}_{5}\right), 11.85$ (s, $\left.1 \mathrm{H}, \mathrm{C}_{12}-\mathrm{OH}\right), 12.79$ (s, $\left.1 \mathrm{H}, \mathrm{C}_{1}-\mathrm{OH}\right) ;{ }^{13} \mathrm{C}$ NMR (75 $\left.\mathrm{MHz}, \mathrm{DMSO}-\mathrm{d}_{6}\right) \delta$, ppm; $15.50\left(1 \mathrm{C}, \mathrm{CH}_{3}\right), 112.80$ (1C, $\left.\mathrm{C}_{6}\right), 115.78\left(2 \mathrm{C}, \mathrm{C}_{10}\right), 117.92\left(2 \mathrm{C}, \mathrm{C}_{11}\right), 124.63(1 \mathrm{C}$, $\left.\mathrm{C}_{4}\right), 124.91\left(1 \mathrm{C}, \mathrm{C}_{5}\right), 126.18\left(1 \mathrm{C}, \mathrm{C}_{2}\right), 129.15\left(1 \mathrm{C}, \mathrm{C}_{9}\right)$, $134.91\left(1 \mathrm{C}, \mathrm{C}_{3}\right), 159.50\left(1 \mathrm{C}, \mathrm{C}_{1}\right), 159.78\left(1 \mathrm{C}, \mathrm{C}_{12}\right)$, $164.34\left(1 \mathrm{C}, \mathrm{C}_{7}\right), 165.07\left(1 \mathrm{C}, \mathrm{C}_{8}\right)$.

6-(5-(4-hydroxy-3-methoxyphenyl)-1,3,4oxadiazol-2-yl)-2-methylphenol

The product $(5 c)$ was purified by flash column chromatography using hexane-ethyl acetate $(4: 1)$ as eluent to afford pale yellow precipitate. Yield0.23 g, 78\%, m.p.(110-115) C, IR (KBr, $v_{\max }$ ' $\left.\mathrm{cm}^{-1}\right) 3282\left(\mathrm{OH}_{\text {vanilin }}\right), 3120\left(\mathrm{OH}_{\text {phenol }}\right), 3012\left(\mathrm{CH}_{\text {aromatic }}\right)$, 2931-2850 ( $\left.\mathrm{CH}_{\text {aliphatic }}\right), 1674(\mathrm{C}=\mathrm{N}), 1591$ 1425(C=C); ${ }^{1} \mathrm{H}$ NMR (400 MHz, DMSO-d 6 ) $\delta$, ppm; $2.07\left(\mathrm{~s}, 3 \mathrm{H}, \mathrm{CH}_{3}\right), 3.72\left(\mathrm{~s}, 3 \mathrm{H}, \mathrm{O}-\mathrm{CH}_{3}\right), 6.73(\mathrm{~m}$, $\left.2 \mathrm{H}, \mathrm{H}_{4}, \mathrm{H}_{10}\right), 7$ (d, J 8.07, $1 \mathrm{H}, \mathrm{H}_{3}$ ), 7.23 (over lap, $\left.2 \mathrm{H}, \mathrm{H}_{5}, \mathrm{H}_{13}\right), 7.67\left(\mathrm{~d}, \mathrm{~J} 8.07,1 \mathrm{H}, \mathrm{H}_{14}\right), 11.74(\mathrm{~s}, 1 \mathrm{H}$, $\left.\mathrm{C}_{12}-\mathrm{OH}\right), 12.64\left(\mathrm{~s}, 1 \mathrm{H}, \mathrm{C}_{1}-\mathrm{OH}\right) ;{ }^{13} \mathrm{C}$ APT $(100 \mathrm{MHz}$, DMSO-d $\left.{ }_{6}\right) \delta$, ppm; $15.96\left(1 \mathrm{C}, \mathrm{CH}_{3}\right), 56.03$ (1C,O$\left.\mathrm{CH}_{3}\right), 109.47\left(1 \mathrm{C}, \mathrm{C}_{10}\right), 113.31\left(1 \mathrm{C}, \mathrm{C}_{6}\right), 115.93(1 \mathrm{C}$, $\left.\mathrm{C}_{13}\right), 118.40\left(1 \mathrm{C}, \mathrm{C}_{14}\right), 123.09\left(1 \mathrm{C}, \mathrm{C}_{4}\right), 125.12(1 \mathrm{C}$, $\left.\mathrm{C}_{5}\right), 125.80\left(1 \mathrm{C}, \mathrm{C}_{9}\right), 126.66\left(1 \mathrm{C}, \mathrm{C}_{2}\right), 135.38\left(1 \mathrm{C}, \mathrm{C}_{3}\right)$, $148.57\left(1 \mathrm{C}, \mathrm{C}_{11}\right), 149.85\left(1 \mathrm{C}, \mathrm{C}_{12}\right), 159.95\left(1 \mathrm{C}, \mathrm{C}_{1}\right)$, $161.68\left(1 \mathrm{C}, \mathrm{C}_{7}\right), 166.77\left(1 \mathrm{C}, \mathrm{C}_{8}\right)$.

\section{6-(5-(4-hydroxy-3,5-dimethoxyphenyl)-1,3,4- oxadiazol-2-yl)-2-methylphenol}

Recrystallization of the crude (5d)product from methanole to give light beige precipitate. Yield $0.27 \mathrm{~g}, 84 \%$, m.p.(122-125) C, IR $\left(\mathrm{KBr}, v_{\max } / \mathrm{cm}^{-1}\right)$ $3510(\mathrm{OH}), 3242\left(\mathrm{OH}_{\text {phenol }}\right), 3091-3008\left(\mathrm{CH}_{\text {aromatic }}\right)$, 2970-2864 $\left(\mathrm{CH}_{\text {aliphatic }}\right), 1630(\mathrm{C}=\mathrm{N}), 1591-1423$ $(\mathrm{C}=\mathrm{C}) ;{ }^{1} \mathrm{H}$ NMR (300 MHz, DMSO-d 6 ) $\delta, \mathrm{ppm} ; 2.05$ (s, 3H, $\left.\mathrm{CH}_{3}\right), 3.69\left(\mathrm{~s}, 6 \mathrm{H}, 2 \times \mathrm{OCH}_{3}\right), 6.72(\mathrm{t}, 1 \mathrm{H}, J$ 7.63, $\left.\mathrm{H}_{4}\right), 6.87\left(\mathrm{~s}, 2 \mathrm{H}, \mathrm{H}_{10}\right), 7.22\left(\mathrm{~d}, 1 \mathrm{H}, J 7.35, \mathrm{H}_{3}\right)$, 7.65 (d, 1H, J7.91, $\left.\mathrm{H}_{5}\right), 11.78\left(\mathrm{~s}, 1 \mathrm{H}, \mathrm{C}_{12}-\mathrm{OH}\right), 12.60$ 
(s, $\left.1 \mathrm{H}, \mathrm{C}_{1}-\mathrm{OH}\right) ;{ }^{13} \mathrm{C}$ NMR $(75 \mathrm{MHz}$, DMSO-d $) \delta$, ppm; $15.52\left(1 \mathrm{C}, \mathrm{CH}_{3}\right), 56.06\left(2 \mathrm{C}, 2 \times \mathrm{OCH}_{3}\right), 104.87(2 \mathrm{C}$, $\left.\mathrm{C}_{10}\right), 112.86\left(1 \mathrm{C}, \mathrm{C}_{6}\right), 117.96\left(1 \mathrm{C}, \mathrm{C}_{4}\right), 124.15(1 \mathrm{C}$, $\left.\mathrm{C}_{9}\right), 124.71\left(1 \mathrm{C}, \mathrm{C}_{5}\right), 126.20\left(1 \mathrm{C}, \mathrm{C}_{2}\right), 134.95\left(1 \mathrm{C}, \mathrm{C}_{3}\right)$, $138.33\left(1 \mathrm{C}, \mathrm{C}_{12}\right), 150.06\left(2 \mathrm{C}, \mathrm{C}_{11}\right), 159.46\left(1 \mathrm{C}, \mathrm{C}_{1}\right)$, $163.30\left(1 \mathrm{C}, \mathrm{C}_{7}\right), 165.65\left(1 \mathrm{C}, \mathrm{C}_{8}\right)$.

6-(5-(2-hydroxy-3,5-di-tertbutylphenyl)-1,3,4oxadiazol-2-yl)-2-methylphenol

The product $(5 \mathrm{e})$ was purified by flash column chromatography using hexane-ethyl acetate $(8: 1)$ as eluent to afford white precipitate. Yield $0.27 \mathrm{~g}$, 72\%, m.p. (225-227) C, IR (KBr, $\left.v_{\max } / \mathrm{cm}^{-1}\right) 3192(\mathrm{OH})$ \& $\left(\mathrm{OH}_{\text {phenol }}\right), 3020\left(\mathrm{CH}_{\text {aromatic }}\right), 2956-2871\left(\mathrm{CH}_{\text {aliphatic }}\right)$, $1610(\mathrm{C}=\mathrm{N}), 1543-1433(\mathrm{C}=\mathrm{C}) ;{ }^{1} \mathrm{H}$ NMR $(300 \mathrm{MHz}$, DMSO-d f $_{6} \delta$, ppm; 1.26-1.38 (s, 18H, $\left.\mathrm{CH}_{3}\right), 2.17$ (s, $\left.3 \mathrm{H}, \mathrm{CH}_{3}\right), 6.86\left(\mathrm{t}, \mathrm{J} 6.9,1 \mathrm{H}, \mathrm{H}_{4}\right), 7.29\left(\mathrm{~m}, 3 \mathrm{H}, \mathrm{H}_{3}, \mathrm{H}_{12}\right.$, $\left.\mathrm{H}_{14}\right), 7.75\left(\mathrm{~d}, 1 \mathrm{H}, J \mathrm{~J} .9, \mathrm{H}_{5}\right), 12.18\left(\mathrm{~s}, 1 \mathrm{H}, \mathrm{C}_{10}-\mathrm{OH}\right)$, 12.38 (s, $\left.1 \mathrm{H}, \mathrm{C}_{1}-\mathrm{OH}\right) ;{ }^{13} \mathrm{C}$ NMR (75 MHz, DMSO-d $)$ $\delta$, ppm; 15.45(1C, $\left.\mathrm{CH}_{3}\right), 29.12\left(3 \mathrm{C}, \mathrm{C}_{16}, \mathrm{CH}_{3}\right), 31.13$ $\left(3 \mathrm{C}, \mathrm{C}_{18}, \mathrm{CH}_{3}\right), 33.72\left(1 \mathrm{C}, \mathrm{C}_{17}\right), 34.50\left(1 \mathrm{C}, \mathrm{C}_{15}\right)$, $116.88\left(1 \mathrm{C}, \mathrm{C}_{6}\right), 117.61\left(1 \mathrm{C}, \mathrm{C}_{9}\right), 119.00\left(1 \mathrm{C}, \mathrm{C}_{4}\right)$, $120.17\left(1 \mathrm{C}, \mathrm{C}_{14}\right), 124.84\left(1 \mathrm{C}, \mathrm{C}_{12}\right), 125.53\left(1 \mathrm{C}, \mathrm{C}_{5}\right)$, $125.69\left(1 \mathrm{C}, \mathrm{C}_{2}\right), 126.07\left(1 \mathrm{C}, \mathrm{C}_{3}\right), 135.64\left(1 \mathrm{C}, \mathrm{C}_{11}\right)$, $140.26\left(1 \mathrm{C}, \mathrm{C}_{13}\right), 154.71\left(1 \mathrm{C}, \mathrm{C}_{10}\right), 159.49\left(1 \mathrm{C}, \mathrm{C}_{1}\right)$, $162.55\left(1 \mathrm{C}, \mathrm{C}_{7}\right), 165.63\left(1 \mathrm{C}, \mathrm{C}_{8}\right)$.

\section{Method B}

Excess of phosphorusoxy chloride $(5 \mathrm{~mL})$ was added dropwise, at room temperature into a mixture of 2-hydroxy-3-methylbenzohydrazide $(0.24 \mathrm{~g}, 1.4 \mathrm{mmol})$ and substituted carboxylic acid $(1.4 \mathrm{mmol})$ in a $250 \mathrm{~mL}$ round bottom flask. The mixture was heated up to $80-90{ }^{\circ} \mathrm{C}$ and stirred for $5 \mathrm{~h}$. Upon cooling, $100 \mathrm{~mL}$ crushed ice was poured into the mixture and stirred for 15 minutes. The $\mathrm{PH}$ of the mixture was adjusted to 7-8 by adding a solution of sodium bicarbonate. The precipitate was filtered, washed with distilled water and dried. The desired product was purified by recrystallization from appropriate solvent or by flash column chromatography

\section{2-(5-(4-chlorophenyl)-1,3,4-oxadiazol-2-yl)-6- methylphenol}

The desired product (5f) was purified by flash column chromatography using hexaneethyl acetate $(4: 0.5)$ as eluent to give white precipitate. Yield $0.33 \mathrm{~g}, 79 \%$, m.p.(171-173) C, IR $\left(\mathrm{KBr}\right.$ max $\left._{\text {max }} / \mathrm{cm}^{-1}\right)$; $3207\left(\mathrm{OH}_{\text {phenol }}\right)$, 3086-3033 $\left(\mathrm{CH}_{\text {aromatic }}\right)$,
2972-2852 $\left(\mathrm{CH}_{\text {aliphatic }}\right), 1610(\mathrm{C}=\mathrm{N}), 1539-1406$ $(\mathrm{C}=\mathrm{C}) ;{ }^{1} \mathrm{H}$ NMR $\left(300 \mathrm{MHz}\right.$, DMSO-d $\left.\mathrm{d}_{6}\right) \delta$, ppm; 2.2 (s, 3H, $\mathrm{CH}_{3}$ ), $6.93\left(\mathrm{t}, \mathrm{J} 8.77,1 \mathrm{H}, \mathrm{H}_{4}\right), 7.11$ (d, J9.01, $\left.2 \mathrm{H}, \mathrm{H}_{11}\right), 7.33\left(\mathrm{~d}, J 8.78,1 \mathrm{H}, \mathrm{H}_{3}\right), 7.73(\mathrm{~d}, J 8.56,1 \mathrm{H}$, $\left.\mathrm{H}_{5}\right), 8.00\left(\mathrm{~d}, J 9.1,2 \mathrm{H}, \mathrm{H}_{10}\right), 10.1(\mathrm{~s}, 1 \mathrm{H}, \mathrm{OH}) ;{ }^{13} \mathrm{C}$ NMR $\left(75 \mathrm{MHz}\right.$, DMSO-d $\left.\mathrm{d}_{6}\right) \delta$, ppm; $15.72\left(1 \mathrm{C}, \mathrm{CH}_{3}\right)$, $107.77\left(1 \mathrm{C}, \mathrm{C}_{6}\right), 119.91\left(1 \mathrm{C}, \mathrm{C}_{4}\right), 121.84\left(1 \mathrm{C}, \mathrm{C}_{9}\right)$, $125.13\left(1 \mathrm{C}, \mathrm{C}_{5}\right), 126.00\left(1 \mathrm{C}, \mathrm{C}_{2}\right), 128.59\left(2 \mathrm{C}, \mathrm{C}_{10}\right)$, $129.62\left(2 \mathrm{C}, \mathrm{C}_{11}\right), 134.72\left(1 \mathrm{C}, \mathrm{C}_{3}\right), 137.00\left(1 \mathrm{C}, \mathrm{C}_{12}\right)$, $154.71\left(1 \mathrm{C}, \mathrm{C}_{1}\right), 162.16\left(1 \mathrm{C}, \mathrm{C}_{8},(\mathrm{C}=\mathrm{N})\right), 164.11(1 \mathrm{C}$, $\left.\mathrm{C}_{7}(\mathrm{C}=\mathrm{N})\right)$.

\section{2-(5-(4-methoxyphenyl)-1,3,4-oxadiazol-2-yl)-6- methylphenol}

Recrystallization of the crude product $(5 \mathrm{~g})$ from ethanol and water to give pale pink precipitate. Yield 0.29 g, 71\%, m.p.(161-164) C, IR (KBr, v max $^{\prime}$ $\left.\mathrm{cm}^{-1}\right)$; $3421\left(\mathrm{OH}_{\text {phenol }}\right), 3097\left(\mathrm{CH}_{\text {aromatic }}\right), 2987-2852$ $\left(\mathrm{CH}_{\text {aliphatic }}\right), 1610(\mathrm{C}=\mathrm{N}), 1543-1429(\mathrm{C}=\mathrm{C}), 1173$ or $1142\left(\mathrm{C}-\mathrm{O}-\mathrm{CH}_{3}\right) ;{ }^{1} \mathrm{H}$ NMR (300 MHz, DMSO-d $\left.\mathrm{d}_{6}\right)$ $\delta$, ppm; $2.28\left(\mathrm{~s}, 3 \mathrm{H}, \mathrm{CH}_{3}\right), 3.87\left(\mathrm{~s}, 3 \mathrm{H}, \mathrm{O}-\mathrm{CH}_{3}\right), 7.02$ $\left(\mathrm{t}, J 7.6,1 \mathrm{H}, \mathrm{H}_{4}\right), 7.19\left(\mathrm{~d}, J\right.$ 9, 2H, $\left.\mathrm{H}_{10}\right), 7.42(\mathrm{~d}, 1 \mathrm{H}$, $\left.\mathrm{H}_{3}\right), 7.82\left(\mathrm{~d}, J 7.9,1 \mathrm{H}, \mathrm{H}_{5}\right), 8.09\left(\mathrm{~d}, J\right.$ 8.9, 2H, $\left.\mathrm{H}_{11}\right)$, $10.18(\mathrm{~s}, 1 \mathrm{H}, \mathrm{OH}) ;{ }^{13} \mathrm{C}$ NMR $\left(75 \mathrm{MHz}\right.$, DMSO-d $\left.\mathrm{d}_{6}\right)$ $\delta$, ppm; $15.70\left(1 \mathrm{C}, \mathrm{CH}_{3}\right), 55.56\left(1 \mathrm{C}, \mathrm{O}-\mathrm{CH}_{3}\right), 107.82$ $\left(1 \mathrm{C}, \mathrm{C}_{6}\right), 114.92\left(2 \mathrm{C}, \mathrm{C}_{11}\right), 115.16\left(2 \mathrm{C}, \mathrm{C}_{10}\right), 119.85$ $\left(1 \mathrm{C}, \mathrm{C}_{4}\right), 124.87\left(1 \mathrm{C}, \mathrm{C}_{5}\right), 125.88\left(1 \mathrm{C}, \mathrm{C}_{2}\right), 128.71$ $\left(1 \mathrm{C}, \mathrm{C}_{9}\right), 134.47\left(1 \mathrm{C}, \mathrm{C}_{3}\right), 154.63\left(1 \mathrm{C}, \mathrm{C}_{1}\right), 162.31$ $\left(1 \mathrm{C}, \mathrm{C}_{7},(\mathrm{C}=\mathrm{N})\right), 162.82\left(1 \mathrm{C}, \mathrm{C}_{8},(\mathrm{C}=\mathrm{N})\right), 163.54$ $\left(1 \mathrm{C}, \mathrm{C}_{12}\right)$.

\section{2,6-di-tert-butyl-4-(5-(2-hydroxy-3-methylphenyl)- 1,3,4-oxadiazol-2-yl)phenol}

The desired product (5h) was purified by flash column chromatography using hexane-ethyl acetate (10:1) as eluent to give orangish yellow precipitate. Yield 0.4 g, 73\%,m.p.(165-168) C, IR $\left(\mathrm{KBr}, v_{\max } / \mathrm{cm}^{-1}\right) ; 3610\left(\mathrm{OH}_{\text {di-tert-buty }}\right), 3176\left(\mathrm{OH}_{\text {phenol }}\right)$, $3097\left(\mathrm{CH}_{\text {aromatic }}\right), 2962-2871$ strong $\left(\mathrm{CH}_{\text {aliphatic }}\right), 1610$ $(\mathrm{C}=\mathrm{N}), 1550-1417(\mathrm{C}=\mathrm{C})$; ${ }^{1} \mathrm{H}$ NMR (300 MHz, DMSO$\left.\mathrm{d}_{6}\right) \delta$, ppm; $1,45\left(\mathrm{~s}, 18 \mathrm{H}, \mathrm{CH}_{3}\right), 2.27\left(\mathrm{~s}, 3 \mathrm{H}, \mathrm{CH}_{3}\right)$, $5.56(\mathrm{~s}, 1 \mathrm{H}, \mathrm{OH}), 7.01\left(\mathrm{t}, 1 \mathrm{H}, J\right.$ J $\left..6, \mathrm{H}_{4}\right), 7.4(\mathrm{~d}, 1 \mathrm{H}$, J 7.2, $\left.\mathrm{H}_{3}\right), 7.78\left(\mathrm{~d}, 1 \mathrm{H}, J\right.$ J.7, $\left.\mathrm{H}_{5}\right), 7.87\left(\mathrm{~s}, 2 \mathrm{H}, \mathrm{H}_{10}\right)$, $10.24(\mathrm{~s}, 1 \mathrm{H}, \mathrm{OH}) ;{ }^{13} \mathrm{C}-\mathrm{NMR}$ (75 MHz, DMSO-d $\left.\mathrm{d}_{6}\right)$ $\delta$, ppm; 15.69 $\left(1 \mathrm{C}, \mathrm{CH}_{3}\right), 29.92\left(1 \mathrm{C}, \mathrm{C} 14, \mathrm{CH}_{3}\right), 34.59$ $\left(1 \mathrm{C}, \mathrm{C}_{13}\right), 107.78\left(1 \mathrm{C}, \mathrm{C}_{6}\right), 114.09\left(1 \mathrm{C}, \mathrm{C}_{9}\right), 119.85$ $\left(1 \mathrm{C}, \mathrm{C}_{4}\right), 123.60\left(1 \mathrm{C}, \mathrm{C}_{5}\right), 124.77\left(2 \mathrm{C}, \mathrm{C}_{10}\right), 125.80$ $\left(1 \mathrm{C}, \mathrm{C}_{2}\right), 134.37\left(1 \mathrm{C}, \mathrm{C}_{3}\right), 139.65\left(1 \mathrm{C}, \mathrm{C}_{11}\right), 154.59$ $\left(1 \mathrm{C}, \mathrm{C}_{1}\right), 157.79\left(1 \mathrm{C}, \mathrm{C}_{12}\right), 163.41\left(1 \mathrm{C}, \mathrm{C}_{7},(\mathrm{C}=\mathrm{N})\right)$, $163.55\left(1 \mathrm{C}, \mathrm{C}_{8},(\mathrm{C}=\mathrm{N})\right)$. 


\section{6,6'-(1,3,4-oxadiazole-2,5-diyl)bis(2-methyl phenol)}

Recrystallization of the crude product (5i)from ethanol and water to give pale yellow precipitate. Yield $0.24 \mathrm{~g}, 61 \%$, m.p.(280 dec.) C, IR $\left(\mathrm{KBr}, v_{\max } / \mathrm{cm}^{-1}\right) ; 3475$ \& $3222\left(\mathrm{OH}_{\text {phenol }}\right), 3022$ $\left(\mathrm{CH}_{\text {aromatic }}\right), 2962-2848\left(\mathrm{CH}_{\text {aliphatic }}\right), 1614(\mathrm{C}=\mathrm{N}), 1547-$ $1481(\mathrm{C}=\mathrm{C}) ;{ }^{1} \mathrm{H}$ NMR $(400 \mathrm{MHz}$, DMSO-d 6 ) $\delta$, ppm; $2.24\left(\mathrm{~s}, 6 \mathrm{H}, 2 \times \mathrm{CH}_{3}\right), 6.95\left(\mathrm{t}, 2 \mathrm{H}, J \mathrm{~J} .62, \mathrm{H}_{4}\right), 7.37$ (d, $\left.2 \mathrm{H}, J 7.22, \mathrm{H}_{3}\right), 7.47\left(\mathrm{~d}, 2 \mathrm{H}, J 7.72, \mathrm{H}_{5}\right), 9.85(\mathrm{~s}$, $2 \mathrm{H}, 2 \mathrm{OH}$ ); ${ }^{13} \mathrm{CAPT}\left(100 \mathrm{MHz}, \mathrm{DMSO}-\mathrm{d}_{6}\right.$ ) $\delta$, ppm; 15.54 $\left(2 \mathrm{C}, 2 \times \mathrm{CH}_{3}\right), 108.67\left(2 \mathrm{C}, \mathrm{C}_{6}\right), 119.54\left(2 \mathrm{C}, \mathrm{C}_{4}\right)$, $125.38\left(2 \mathrm{C}, \mathrm{C}_{5}\right), 126.06\left(2 \mathrm{C}, \mathrm{C}_{2}\right), 134.14\left(2 \mathrm{C}, \mathrm{C}_{3}\right)$, $153.33\left(2 \mathrm{C}, \mathrm{C}_{1}\right), 159.62\left(2 \mathrm{C}, 2 \times \mathrm{C}_{7}\right)$.

\section{Antioxidant DPPH assay}

The assay was performed as reported by Gerhauser et al. ${ }^{33}$. Five microliters of the sample (dissolved in ethanol) was added into $195 \mu \mathrm{L}$ of $100 \mu$ M DPPH reagent in ethanol (96\%) and mixed in a 96-well plate. The intensity of the colour was measured for $3 \mathrm{~h}$ at an interval of $20 \mathrm{~min}$ at $515 \mathrm{~nm}$. Ascorbic acid and BHT were used as references

\section{FRAP assay}

The FRAP assay was performed according to the Benzie and Strain method ${ }^{34}$. The FRAP reagent was prepared by combining $300 \mathrm{mM}$ acetate buffer and $10 \mathrm{mM}$ 2,4,6-tripyridyl-s-triazine (TPTZ) solution in $40 \mathrm{mMHCl}$ and $20 \mathrm{mM} \mathrm{FeCl}_{3} \cdot 6 \mathrm{H}_{2} \mathrm{O}$, in a ratio of 10:1:1. The FRAP reagent was incubated at $37^{\circ} \mathrm{C}$ prior to use. Ten microliters of the sample was reconstituted in the carrier (solventor ultrapure water) and mixed with $300 \mu \mathrm{L}$ of FRAP reagent. The mixture was incubated at $37^{\circ} \mathrm{C}$ for $4 \mathrm{~min}$ in a microplate reader. The absorbance of the complex was performed at $593 \mathrm{~nm}$.

\section{Determination of the antibacterial activity}

The antibacterial activities of the following synthesized compounds (2), (3a-e), (4a-e)and(5a-i) were tested against standard typed strains of eight bacteria. They were obtained from the Central service laboratory-college education for pure science-lbn Alhaitham . These microorganism's strains consist of Gram negative bacteria: Acinetobactercalcoaceticus ATCC 23055, Escherichia coli ATCC10538, Pseudomonas aeruginosaATCC15442, Salmonella typhimurium ATCC 14028. The Gram positive bacteria were Bacillus subtilis ATCC 6051, Enterococcus faecalis, ATCC 29212 Streptococcus pyogenesATCC 19615, Staphylococcus aureus ATCC 29213. The antibacterial activities were assayed in terms of minimal inhibitory concentrations (MICs) by employing the dilution assays according to the CLSI guidelines ${ }^{35}$. The dimethyl sulfoxide (DMSO) which was used as solvent was included as (negative control) with concentrations between 0.05 to 0.5 $\mathrm{mg} / \mathrm{mL}$ of synthesized compounds. Amoxicillin and kanamycin in DMSO (commercial antibiotics). In the same concentrations range were taken as a positive control. Bacterial stock cultures were supplied on nutrient agar plates. A loopful of bacterial cultures from the nutrient agar plates were diluted with $100 \mathrm{~mL}$ nutrient broth in $250 \mathrm{~mL}$ a side arm Erlenmeyer flask and aerobically incubated at $37^{\circ} \mathrm{C}$ for overnight with continuous shaking. After incubation, cultures were diluted with fresh media to give an O.D of $600 \mathrm{~nm}$ of 0.1 volum. Fifty $\mu \mathrm{L}$ of standardized $18 \mathrm{~h}$ incubated bacterial culture was introduced into test tubes of $5 \mathrm{~mL}$ media (Muelen Hintan broth) followed by the addition of various concentration of the studied compounds. The MIC was estimated as the lowest concentration that inhibits the growth of the bacterial strains. All assays were performed in triplicate and MIC's values were noted in $\mathrm{mg} / \mathrm{mL}$.

\section{RESULT AND DISCUSSION}

6-(5-thio-1,3,4-oxadiazol-2-yl)-2methylphenol(2) successfully synthesized from 2-hydroxy-3-methylbenzohydrazide following the procedure depicted in Scheme 1. The structure of compound (2) was conrmed by spectroscopic analysis. The IR spectrum was displayed no signals of carbonyl of the hydrazide at $1650 \mathrm{~cm}^{-1}$ and $\mathrm{NH}_{2}$ at 3323-3267 $\mathrm{cm}^{-1}$. A new signal band of $\mathrm{C}=\mathrm{N}$ appeared at $1606 \mathrm{~cm}^{-1}$ and for $\mathrm{C}=\mathrm{S}$ at $1122 \mathrm{~cm}^{-1}$. The ${ }^{1} \mathrm{H}$ NMR showed disappearing the broad signal of amine $\left(\mathrm{NH}_{2}\right)$ at $4.69 \mathrm{ppm}$ moreover, the protons of 2-methylgroup, $\mathrm{NH}$ and phenol were appeared at their expected area.Th ${ }^{13} \mathrm{CAttached-Proton-}$ Test (APT) Spectrum exhibited five negative peaks (pointing downwards) belonged to five quaternary carbons $\mathrm{C}_{1}, \mathrm{C}_{2}, \mathrm{C}_{6}, \mathrm{C}_{7}(\mathrm{C}=\mathrm{N}), \mathrm{C}_{8}(\mathrm{C}=\mathrm{S})$ at (154.30, $127.04,109.65,160.59,177.24) \mathrm{ppm}$ respectively. In addition to that, the $\mathrm{CH}_{3}$ and $\mathrm{CH}$ were located as positive peak for $\mathrm{CH}_{3}, \mathrm{C}_{3}, \mathrm{C}_{4}, \mathrm{C}_{5}$ at $(16.51,135.11$, 
120.51, 126.35) ppm respectively. The electron ionization mass (EIMs) spectrum showed the value of the molecular ion $\mathrm{M}^{*+}=208$ as well it is the same value of base peak (100\%) .

Alkylation of 6-(5-thio-1,3,4-oxadiazol-2-yl)2-methylphenol achieved successfully by alkylation reaction in DMF. Five alkyl halides were used in the presence of potassium carbonate at ambient temperature. The newly synthesized compounds (3a-e) were characterized from their IR, 1D NMR and EIMs spectra. The IR spectra displayed the disappearing of signal forthione, besides the appearing of the new function group of alkyl such as $\mathrm{C}=\mathrm{O}$ of ester at $1728 \mathrm{~cm}^{-1}$ for compound (3d), $\mathrm{C}=\mathrm{O}$ of ketone at $1678 \mathrm{~cm}^{-1}$ for compound (3c) as well the $\mathrm{C}=\mathrm{N}$ and $\mathrm{NH}$ for benzimidazol at $1618 \mathrm{~cm}^{-1}$ and $3174 \mathrm{~cm}^{-1}$ respectively for the compound (3b). The ${ }^{1} \mathrm{H}$ NMR spectra showed singlets at $\delta$ 3.34-5.16 ppm which were assigned to the $\mathrm{SCH}_{2}$, moreover the rest protons of alkyl group and the 2-methyl phenol were appeared at their expected area. Furthermore, the ${ }^{13} \mathrm{C}$ NMR and ${ }^{13} \mathrm{C}$ APT of the 6-(5-(alkylthio)1,3,4-oxadiazol-2-yl)-2-methylphenol (3a-e) showed characteristic peak in the $\delta$ 162.44-163.73 ppm, which was assigned to new $\mathrm{C}=\mathrm{N}$ besides the peaks of thioalkyl group. ${ }^{13} \mathrm{C}$ APT spectrum of compound (3a) displayed the $\mathrm{CH}_{3}$ of ethyl group located as positive peak at $15.3 \mathrm{ppm}$, while the $\mathrm{CH}_{2}$ located as negative peak at $27.25 \mathrm{ppm}$. The APT spectrum of compound (3b) showed new peak of 2-methylbenzimidazole. The $\mathrm{CH}_{2}$ besides $\mathrm{C}_{1}, \mathrm{C}_{2}, \mathrm{C}_{6}, \mathrm{C}_{7}, \mathrm{C}_{8}, \mathrm{C}_{10}$ and $\mathrm{C}_{11}$ were appeared at the negative position, while $\mathrm{CH}_{3}$, $\mathrm{C}_{3}, \mathrm{C}_{4}, \mathrm{C}_{5}, \mathrm{C}_{12}$ and $\mathrm{C}_{13}$ were exhibited as positive<smiles>[R]c1nnc(-c2cccc(C)c2O)o1</smiles>

Scheme 1. Synthetic route of compound (1-5i)

Table 1: Alkyl group and some selected properties of compounds (2-3e)

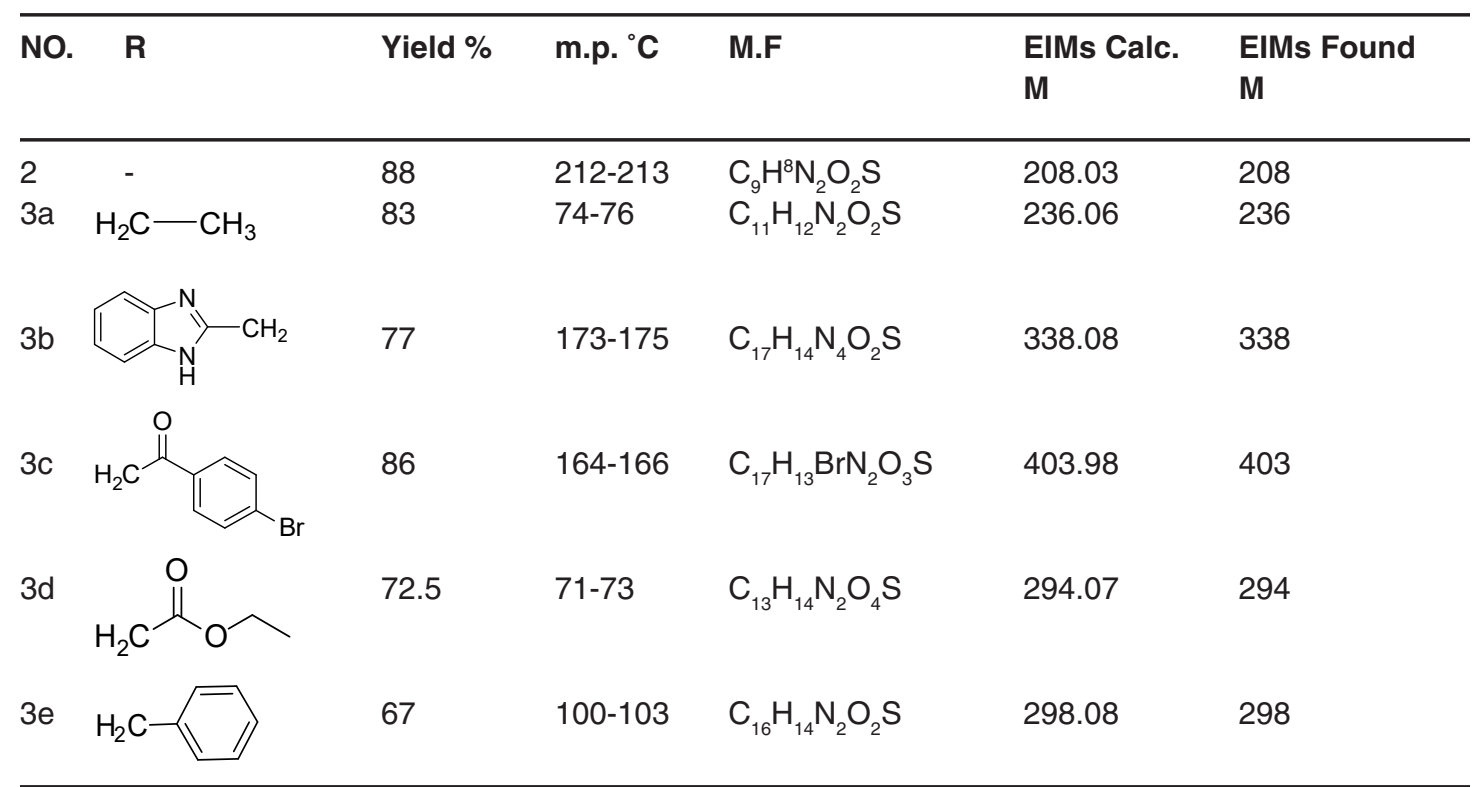


Table 2: Aryl group and some selected properties of compounds (4a-5i)

\begin{tabular}{|c|c|c|c|c|c|c|}
\hline No. & $\mathrm{Ar}$ & Yield \% & m.p. ${ }^{\circ} \mathrm{C}$ & M.F & $\begin{array}{l}\text { EIMs Calc. } \\
\text { M }\end{array}$ & $\begin{array}{l}\text { EIMs Found } \\
\text { M }\end{array}$ \\
\hline $4 a$ & & 67 & $173-174$ & $\mathrm{C}_{16} \mathrm{H}_{16} \mathrm{~N}_{2} \mathrm{O}_{2}$ & 268.12 & 268 \\
\hline $4 b$ & & 78 & $240-242$ & $\mathrm{C}_{15} \mathrm{H}_{14} \mathrm{~N}_{2} \mathrm{O}_{3}$ & 270.1 & 270 \\
\hline $4 c$ & & 83 & $203-206$ & $\mathrm{C}_{16} \mathrm{H}_{16} \mathrm{~N}_{2} \mathrm{O}_{4}$ & 300.11 & 300 \\
\hline $4 d$ & & 81 & $210-213$ & $\mathrm{C}_{17} \mathrm{H}_{18} \mathrm{~N}_{2} \mathrm{O}_{5}$ & 330.12 & 330 \\
\hline $4 \mathrm{e}$ & & 77 & $205-208$ & $\mathrm{C}_{23} \mathrm{H}_{30} \mathrm{~N}_{2} \mathrm{O}_{3}$ & 382.23 & 382 \\
\hline $5 a$ & & 73 & $158-160$ & $\mathrm{C}_{16} \mathrm{H}_{14} \mathrm{~N}_{2} \mathrm{O}_{2}$ & 266.11 & 266 \\
\hline $5 b$ & & 75 & $224-227$ & $\mathrm{C}_{15} \mathrm{H}_{12} \mathrm{~N}_{2} \mathrm{O}_{3}$ & 268.08 & 268 \\
\hline $5 c$ & & 78 & $110-115$ & $\mathrm{C}_{16} \mathrm{H}_{14} \mathrm{~N}_{2} \mathrm{O}_{4}$ & 298.1 & 298 \\
\hline $5 d$ & & 84 & $122-125$ & $\mathrm{C}_{17} \mathrm{H}_{16} \mathrm{~N}_{2} \mathrm{O}_{5}$ & 328.11 & 328 \\
\hline $5 e$ & & 72 & $225-227$ & $\mathrm{C}_{23} \mathrm{H}_{28} \mathrm{~N}_{2} \mathrm{O}_{3}$ & 380.21 & 379 \\
\hline $5 f$ & & 79 & $171-173$ & $\mathrm{C}_{15} \mathrm{H}_{11} \mathrm{C}_{1} \mathrm{~N}_{2} \mathrm{O}_{2}$ & 286.05 & 286 \\
\hline $5 g$ & & 71 & $161-164$ & $\mathrm{C}_{16} \mathrm{H}_{14} \mathrm{~N}_{2} \mathrm{O}_{3}$ & 282.1 & 282 \\
\hline $5 \mathrm{~h}$ & & 73 & $165-168$ & $\mathrm{C}_{23} \mathrm{H}_{28} \mathrm{~N}_{2} \mathrm{O}_{3}$ & 380.21 & 379 \\
\hline $5 i$ & & 61 & 280 dec. & $\mathrm{C}_{16} \mathrm{H}_{14} \mathrm{~N}_{2} \mathrm{O}_{3}$ & 282.1 & 282 \\
\hline
\end{tabular}


peaks. The ${ }^{13} \mathrm{C}$ NMR of compound (3c) and (3d) showed the $\mathrm{SCH}_{2}$ group at $40.83 \mathrm{ppm}$ and 35.92 ppm respectively as well the ketone carbonyl group of (3c) located at $192.44 \mathrm{ppm}$ and the carbonyl of ester of (3d) located at $167.62 \mathrm{ppm}$. The alkyl group and some physical properties were tabulated in Table 1.

The Mass spectra showed the molecular ions $\left(\mathrm{M}^{\circ}\right)$ of the synthesized compounds (3a-e). The base peak was showed the same value of the molecular ion as in compounds (3a, 3d) and (3e). The base beak of compound ( $3 b$ ) was appeared as 2-methyl benzimidazole carbocation [BIMCH2+], while it appeared for compound (3c) as 6-(5-thio1,3,4-oxadiazol-2-yl)-2-methylphenol carbocation.

The N' (substituted benzylidene)2- hydroxy3-methylbenzohydrazide (4a-e) (hydrazones) were synthesized as an intermediate compounds in the formation of the 1,3,4-oxadiazole ring (5a-e). the reaction of hydrazide( 1 ) with substituted benzaldehyde to produce the corresponding hydrazones with significant yield. The hydrazones(4a-e) were characterized by IR, ${ }^{1} \mathrm{D}-\mathrm{NMR}$ and EIMs. Furthermore, the HMBC was used with compound (4c). The aryl group and some selective physical properties were tabulated at Table 2.The IR spectra exhibited new signal of the imine group $(\mathrm{C}=\mathrm{N})$ at $(1633-1603) \mathrm{cm}^{-1}$. The Carbonyl group of hydrazone displayed at (17351630) $\mathrm{cm}^{-1}$.

The ${ }^{1} \mathrm{H}-\mathrm{NMR}$ of these compounds showed disappearance of the $\mathrm{NH}_{2}$ peak at $4.69 \mathrm{ppm}$. Moreover, new peaks appeared such as $\mathrm{C}=\mathrm{N}$ at (8.39-8.65) ppm. The protons peaks of the aromatic aldehyde were appeared at their expected area and the $\mathrm{OH}$ signal appeared at range (12.43-12.80) ppm, as well the $\mathrm{NH}$ signal appeared at (11.86-12.23) ppm. The NMR spectra exhibited the substituted group of aldehyde. The three protons of methyl group for compound (4a) appeared at $2.36 \mathrm{ppm}$. The para hydroxyl group of compound (4b) appeared as broad singlet signal at $10.02 \mathrm{ppm}$, the methoxy group for compounds (4c) and (4d) appeared at $3.42 \mathrm{ppm}$ and $3.83 \mathrm{ppm}$ integrating for three and six protons respectively. The di-tert-butyl group for compound (4e) appeared as two singlets with nine protons integrating for each peak.

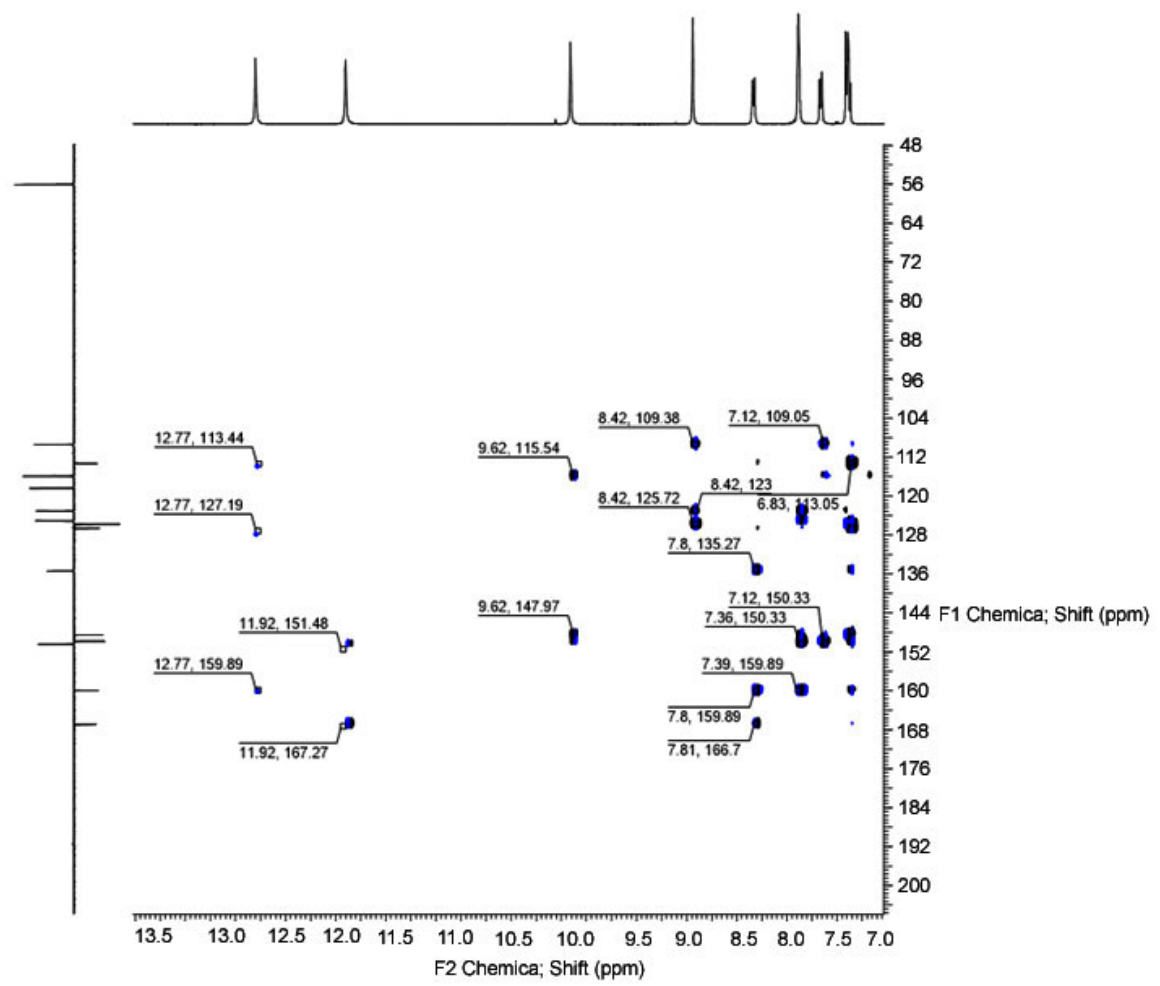

Fig. 1: HMBC spectrum ,expansion aria of compound (4c) 
The ${ }^{13} \mathrm{CNMR},{ }^{13} \mathrm{C}$ APT spectra showed new carbons of aromatic substituted aldehyde besides the interesting peak were assigned to $\mathrm{CH}=\mathrm{N}$ at $148.12-152.11 \mathrm{ppm}$. Moreover, the ${ }^{13} \mathrm{CNMR}$ assigned the substituted group at the aromatic aldehyde. The methyl group of compound (4a) appeared at $21.02 \mathrm{ppm}$. The carbon attached with para hydroxyl group of compound (4b) appeared at $159.73 \mathrm{ppm}$, the methoxy group of compound (4c) and (4d) appeared at $56.03 \mathrm{ppm}$ and $35.00 \mathrm{ppm}$ respectively. The carbons of two di-tert- butyl group of compound (4e) appeared at $29.25 \mathrm{ppm}$ and 31.25 ppm.
The HMBC was used with compound (4c) to solve any confusing with ${ }^{1} \mathrm{H}$ and ${ }^{13} \mathrm{C}$ NMR. HMBC spectrum disclosed the correlation for long distance coupling $J_{3}$ and weak for $J_{2}$. The HMBC spectrum exhibited three correlations at 12.77-113.44 ppm, 12.77-127.19 ppm and 12.77-159.89 ppm as displayed in Figure 1.

These correlations disclosed the relations between the $\mathrm{OH}$ of 2-methylphenol with $\mathrm{C}_{6}$ and $\mathrm{C}_{2}$ as $J_{3}$, while the correlation with $\mathrm{C}_{1}$ exhibited as $J_{2}$.Although, the protons at $11.92 \mathrm{ppm}$ and 9.62 ppm displayed just two correlations, However the

Table 3: Antioxidant properties of compound (2) and their alkyl (3a-e)

\begin{tabular}{|c|c|c|c|}
\hline $\begin{array}{l}\text { Compound } \\
\text { No. }\end{array}$ & Alkyl Group & $\begin{array}{l}\text { DPPH Inhibition } \% \pm \text { SD a } \\
100 \mu \mathrm{g} / \mathrm{mL}\end{array}$ & $\begin{array}{l}\mathrm{IC}_{50} \pm \mathrm{SEM} \mathrm{b} \\
(100 \mu \mathrm{g} / \mathrm{mL})\end{array}$ \\
\hline 2 & - & $68.21 \pm 0.0243$ & $43.101 \pm 0.0451$ \\
\hline $3 a$ & & $34.16 \pm 0.0513$ & $100>$ \\
\hline $3 b$ & & $66.72 \pm 0.0129$ & $49.03 \pm 0.0335$ \\
\hline $3 c$ & & $45.07 \pm 0.037$ & $89.90 \pm 0.0172$ \\
\hline $3 d$ & & $38.63 \pm 0.0662$ & $100>$ \\
\hline $3 e$ & & $48.66 \pm 0.0212$ & $84.08 \pm 0.0568$ \\
\hline 2-Me phenol & & $20.15 \pm 0.0189$ & $100>$ \\
\hline BHT & & $66.03 \pm 0.022$ & $79.835 \pm 0.015$ \\
\hline Ascorbic acid & & $90.65 \pm 0.025$ & $22.71 \pm 0.020$ \\
\hline
\end{tabular}

a Standard deviation (SD) value in FRAP was between 0.01-0.16; bSEM standard mean error and $\mathrm{IC}_{50}$ : $50 \%$ effective concentration 
HMBC allowed to distinguished between the $\mathrm{NH}$ of hydrazone and the $\mathrm{OH}$ of 3-methoxyphenol. The peak at 11.92 ppm showed correlation with $\mathrm{C}_{8}(\mathrm{C}=\mathrm{N})$ at 11.92-151.48 ppm as $J_{3}$. However, the correlation with $\mathrm{C}_{7}(\mathrm{C}=\mathrm{O})$ appeared as $J_{2}$. These correlations indicated that the proton at $9.62 \mathrm{ppm}$ belongs to Hydroxyl group of 3-methoxyphnol. The two characteristic correlations at 9.62-115.54 ppm and 9.62-147.97 ppm indicated the correlation between the proton of $\mathrm{OH}$ group and $\mathrm{C}_{13}$ as well with $\mathrm{C}_{11}$. The most important correlation depicted in Figure 2.

Furthermore, the HMBC spectrum allowed distinguishing between $\mathrm{C}_{1}$ and $\mathrm{C}_{12}$. The $\mathrm{C}_{1}$ at 159.89 ppm showed correlations with $\mathrm{OH}$ of 2-methylphenol as mentioned earlier besides the correlation with $\mathrm{H}_{3}$ at 7.39-159.89 ppm and correlation with $\mathrm{H}_{5}$ at 7.8-159.89 ppm as $J_{3}$. The $\mathrm{C}_{12}$ exhibited correlation with $\mathrm{H}_{10}$ at 7.36-150.33 ppm and with $\mathrm{H}_{14}$ at 7.12$150.33 \mathrm{ppm}$ as $J_{3}$. As demonstrated in HMBC key correlations. Furthermore, the structures of these compounds were characterized from their mass spectra. The mass spectra confirmed the molecular weight of these compounds from their molecular ion, base peak and their fragmentations.

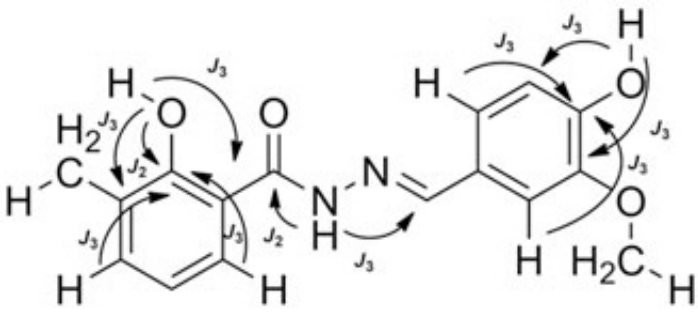

Fig. 2: Selected HMBC correlations of compound (4c)
The newly synthesized compounds of 6-(5(aryl)-1,3,4-oxadiazol-2-yl)-2-methylphenol (5a-i) were successfully synthesized by two methods. The first method was from cyclization of the hydrazones(4a-e)in the presence of bromine in glacial acetic acid. The second method, from reacting the hydrazide(1) with substituted benzoic acid in the presence of phosphorusoxy chloride. The new compounds were characterized by IR, NMR and mass spectroscopy. The IR spectra showed the $\mathrm{OH}$ group at $3471-3120 \mathrm{~cm}^{-1},\left(\mathrm{CH}_{\text {aliphatic }}\right)$ at 2987$2746 \mathrm{~cm}^{-1},\left(\mathrm{CH}_{\text {aromatic }}\right)$ at $3097-3008 \mathrm{~cm}^{-1}$ and $\mathrm{C}=\mathrm{N}$ at $1622-1606 \mathrm{~cm}^{-1}$. The ${ }^{1} \mathrm{H}$ NMR spectra exhibited that the $\mathrm{CH}=\mathrm{N}$ peak and the $\mathrm{NH}$ were disappeared after cyclization the hydrazones. The NMR spectra of compounds which synthesized from cyclization the hydrazide with the carboxylic acid exhibited disappearing of the $\mathrm{NH}, \mathrm{NH}_{2}$ and $\mathrm{OH}$ of carboxylic acid. Furthermore, the protons of the 2-methylphenol group appeared at their expected area. The ${ }^{1} \mathrm{H}$ NMR spectra displayed the methyl group at 2.03-2.28 ppm, integrating for three protons, while in compound (5i) appeared at $2.24 \mathrm{ppm}$ integrating for six protons. As well the protons of 5-ary group of the 1,3,4-oxadiazoe appeared in their expectedr egion. The 4-methyl group of compound (5a) appeared at $2.2 \mathrm{ppm}$ as singlet peak. The para hydroxyl of compound (5b) appeared at $12.79 \mathrm{ppm},{ }^{1} \mathrm{H}$ NMR of compound (5c) showed singlet at $3.72 \mathrm{ppm}$, integrating for three protons disclosed to 3-methoxyl. The multiples at $6.73 \mathrm{ppm}$, integrating for two protons disclosed the $\mathrm{H}_{4}$ and $\mathrm{H}_{10}$. The $\mathrm{H}_{13}$ and $\mathrm{H}_{14}$ appeared at $7.23 \mathrm{ppm}$ and $7.67 \mathrm{ppm}$ respectively. The compound (5d) exhibited singlet peak at 3.69 ppm for two methoxy groups. compound (5h) showed singlet at $1.45 \mathrm{ppm}$ for two

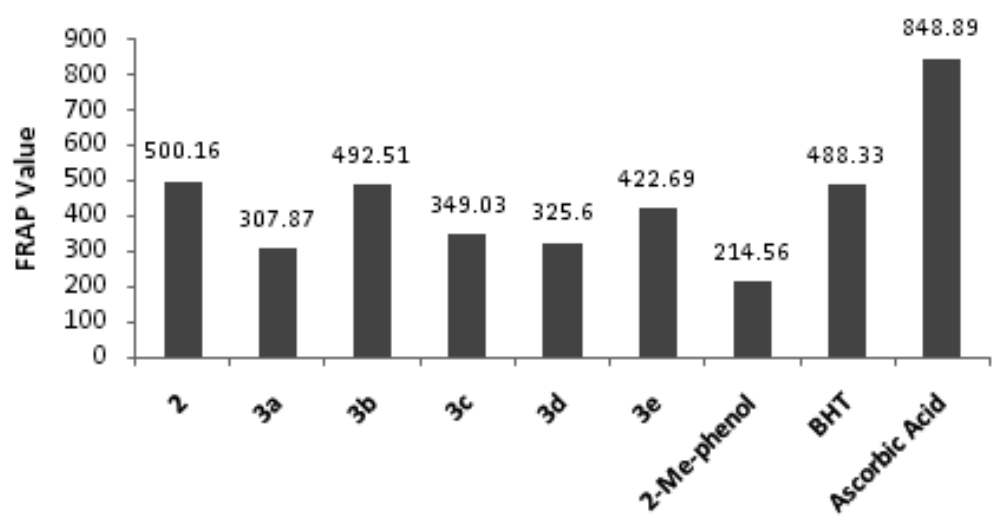

Fig. 3: FRAP value of compound (2) and their alkyl (3a-e) 
Table 4: DPPH inhibition \% and IC ${ }_{50}$ of compound (4a-e) and (5a-i)

\begin{tabular}{|c|c|c|c|}
\hline No. & $\mathrm{Ar}$ & $\begin{array}{l}\text { DPPH Inhibition } \% \pm \text { SD a } \\
100 \mu \mathrm{g} / \mathrm{mL}\end{array}$ & $\begin{array}{l}\mathrm{IC}_{50} \pm \mathrm{ESM} \mathrm{b} \\
(100 \mu \mathrm{g} / \mathrm{mL})\end{array}$ \\
\hline $4 a$ & & $65.72 \pm 0.0183$ & $100>$ \\
\hline $4 b$ & & $69.83 \pm 0.0311$ & $78.32 \pm 0.027$ \\
\hline $4 c$ & & $74.65 \pm 0.0615$ & $60.04 \pm 0.0198$ \\
\hline $4 d$ & & $91.14 \pm 0.0187$ & $38.09 \pm 0.061$ \\
\hline $4 e$ & & $87.31 \pm 0.030$ & $43.15 \pm 0.0306$ \\
\hline $5 a$ & & $62.66 \pm 0.029$ & $100>$ \\
\hline $5 b$ & & $62.18 \pm 0.021$ & $81.96 \pm 0.022$ \\
\hline $5 c$ & & $68.9 \pm 0.027$ & $80.11 \pm 0.014$ \\
\hline $5 d$ & & $82.14 \pm 0.023$ & $49.04 \pm 0.018$ \\
\hline $5 e$ & & $78.33 \pm 0.034$ & $53,08 \pm 0.012$ \\
\hline $5 f$ & & $41.70 \pm 0.052$ & $100>$ \\
\hline $5 g$ & & $60.72 \pm 0.041$ & $82.39 \pm 0.027$ \\
\hline $5 \mathrm{~h}$ & & $93.09 \pm 0.0 .33$ & $31.5 \pm 0.0189$ \\
\hline $5 i$ & & $74.31 \pm 0.062$ & $57.83 \pm 0.0171$ \\
\hline 2-Me phenol & & $20.15 \pm 0.0189$ & $100>$ \\
\hline BHT & & $66.03 \pm 0.022$ & $79.835 \pm 0.015$ \\
\hline Ascorbic acid & & $90.65 \pm 0.025$ & $22.71 \pm 0.020$ \\
\hline
\end{tabular}


tert-butyl groups, while the two tert-butyl groups for compound (5e) exhibited at two singlet $1.26 \mathrm{ppm}$ and $1.38 \mathrm{ppm}$.

The ${ }^{13} \mathrm{C}$ NMR spectra displayed two characteristic peaks at 161.68-164.34 ppm and 162.28-165.65ppm belonged to $C_{7}$ and $C_{8}$ of the oxadiazole ring. The methyl of the 2-methylphenol of compound (5a) appeared at $15.26 \mathrm{ppm}$ while the 4-methyl appeared at $20.83 \mathrm{ppm}$. The Carbon bearing the para hydroxyl group of compound (5b) was appeared at $159.78 \mathrm{ppm}$. The spectrum of compound (5c) showed the methoxy group at 56.03 ppm and $56.06 \mathrm{ppm}$ for two methoxy groups of compound $(5 d)$. The six methyl of 3,5-di-tert-butyl group of compound (5h) appeared as single peak at $29.92 \mathrm{ppm}$ whereas the six methyl of 2,4-di-tert-butyl of compound (5e) appeared as two single peaks at $29.12 \mathrm{ppm}$ and $31.13 \mathrm{ppm}$. The values molecular ion, base peak and their fragmentation confirmed the structures of the newly synthesized oxadiazole by mass spectroscopy.

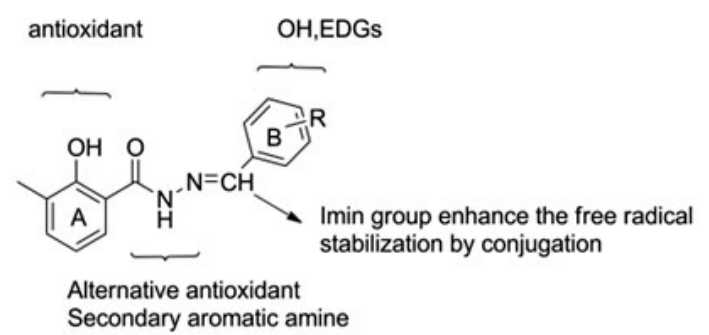

Fig. 4: Relationship between structure of hydrazones and the antioxidant activity

\section{Antioxidant properties}

The antioxidant activities of the newly synthesized compounds (2, 3a-e, 4a-e and 5a-i) were screened by DPPH assay which undergoes a hydrogen atom transfer mechanism (HAT $)^{36}$ also they screened by FRAP assay which is prefer single electron transfer $(\mathrm{SET})^{37}$. The radical scavenging power in both assays was compared with three standard antioxidants, 2-methylphenol, BHT and ascorbic acid. Compound (2) exhibited highest inhibition percentage in DPPH assay than their alkyls (3a-e). This diminution of antioxidant properties of alkyl derivative in compound (2) could be attributed to disappearing the thioamide group which were reported as free radical scavengers. ${ }^{38}$ Moreover, the NHCS group is considered as a part of thiourea system which is known as effective antioxidant. ${ }^{39}$ The alkyls derivatives of compound (2)showed inhibition percentage higher than 2-methylphenol $(2 \mathrm{Me}$ Phenol). Compounds (2) and (3b) exhibited DPPH inhibitions slightly higher than $\mathrm{BHT}$, whereas their $\mathrm{IC}_{50}$ value was less than $\mathrm{BHT}$, as displayed in Table 3

The FRAP value of compounds (2) and (3a-e) as depicted in Figure 3, were compatible with DPPH results as displayed in Figure 3 . The FRAP value of compound (2) showed the highest antioxidant activity than their alkyl derivatives. The decreasing in FRAP value of compounds (3a-e)could be attributed to losing the NHCS group as mentioned earlier. Compound ( $3 b$ ) with thio methylbenzimidazole exhibited higher antioxidant properties than the other thioalkeys in both assays and that could be attributed

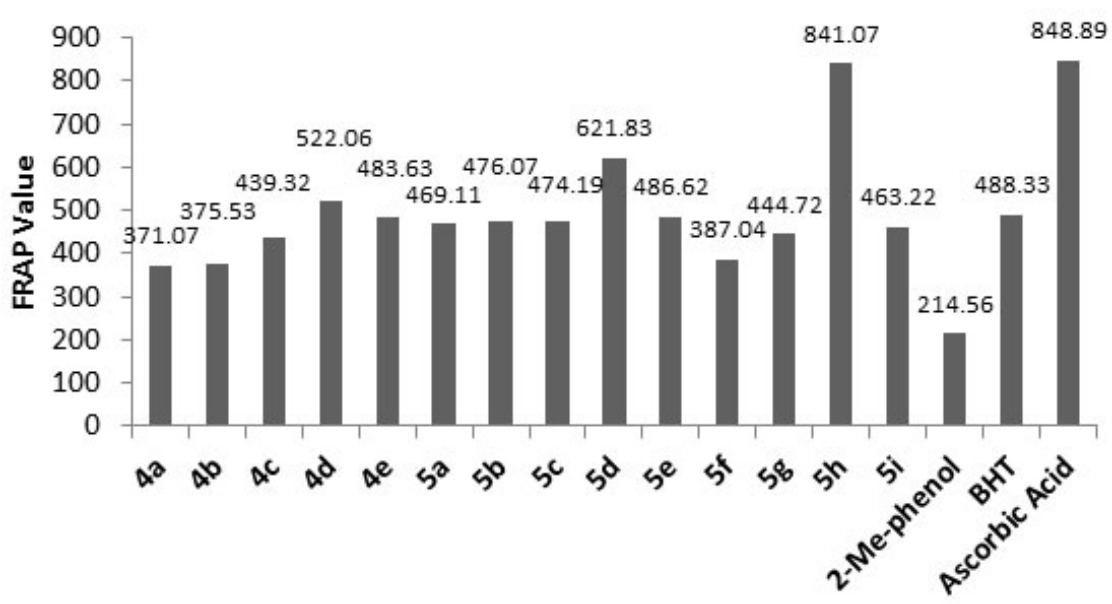

Fig. 5: FRAP value of compounds (4a-e) and (5a-i) 
to precipitation of $\mathrm{NH}$ of banzimidazole in antioxidant properties ${ }^{40-42}$. Assuming that the formation of oxadiazole ring at position six of the 2-methyl phenol could play an pivotal role to enhances the antioxidant ability by increasing the steric hindrance which lead to increase the antioxidant capacity ${ }^{43}$.

The hydrazones (4a-e) exhibited antioxidant ability in both assays higher than their corresponding oxadiazole(5a-e) and that could be attributed to the generic structure of the newly synthesized hydrazones (4a-e), as depicted in Table 4.

The structure of these hydrazons include a recognized free radical scavenger as phenol group (ring $\mathrm{A}$ ), the $\mathrm{NH}$ as secondary amine which considered as alternative secondary antioxidant, the imine group $(\mathrm{N}=\mathrm{CH})$ as shown in Figure 4 which enable resonance with aromatic (ring $\mathrm{B}$ ) and their substituted group such as $4-\mathrm{CH}_{3}, 4-\mathrm{OH}, 3-\mathrm{OMe}-4-$ $\mathrm{OH}, 3,5-$ di-OMe-4-OH and 2-OH-3,5-di-tert-butyl group which act as electron donating group (EDG) to immerse the radical scavenging activity of phenols ${ }^{15}$. These EDGs enable to lowering the bond dissociation enthalpy (BDE) of the phenol (ring B) as well increase the stabilization of the phenoxyl $\left.\right|^{44}$.

Compound (4a) with 4-methyl group exhibited lowest antioxidant among the hydrazons however; their DPPH scavenging activity was

Table 5: Antibacterial activities of synthesized compound

NO Bacteria/MICs $(\mathrm{mg} / \mathrm{mL})$

Gram-negative bacteria

Gram-positive bacteria

\begin{tabular}{|c|c|c|c|c|c|c|c|c|}
\hline & $\begin{array}{l}\text { Acineto } \\
\text { bacter } \\
\text { calcoaceticus }\end{array}$ & $\begin{array}{l}\text { Escherichia } \\
\text { coli }\end{array}$ & $\begin{array}{l}\text { Pseudo } \\
\text { monas } \\
\text { aeruginosa }\end{array}$ & $\begin{array}{l}\text { Salmo } \\
\text { nella } \\
\text { a typhimurium }\end{array}$ & $\begin{array}{l}\text { Bacillus } \\
\text { subtilis }\end{array}$ & $\begin{array}{l}\text { Enteroc } \\
\text { occus } \\
\text { faecalis }\end{array}$ & $\begin{array}{l}\text { Strepto } \\
\text { coccus } \\
\text { pyogenes }\end{array}$ & $\begin{array}{l}\text { Staphyl } \\
\text { aureus }\end{array}$ \\
\hline 2 & 0.3 & $>0.5$ & $>0.5$ & 0.4 & 0.05 & 0.1 & 0.1 & 0.15 \\
\hline $3 a$ & nd & nd & nd & nd & $>0.5$ & nd & $>0.5$ & $>0.5$ \\
\hline $3 b$ & 0.35 & $>0.5$ & 0.35 & $>0.5$ & 0.15 & 0.2 & 0.1 & 0.05 \\
\hline $3 c$ & $>0.5$ & 0.5 & $>0.5$ & $>0.5$ & 0.25 & 0.35 & 0.4 & 0.5 \\
\hline $3 d$ & nd & $>0.5$ & nd & $>0.5$ & $>0.5$ & $>0.5$ & $>0.5$ & $>0.5$ \\
\hline $3 e$ & 0.5 & 0.5 & $>0.5$ & 0.5 & 0.4 & $>0.5$ & 0.5 & $>0.5$ \\
\hline $4 a$ & $>0.5$ & $>0.5$ & 0.35 & $>0.5$ & 0.35 & 0.5 & 0.3 & 0.35 \\
\hline $4 b$ & 0.35 & $>0.5$ & 0.4 & 0.25 & 0.20 & 0.35 & 0.25 & 0.3 \\
\hline $4 c$ & 0.3 & 0.5 & 0.2 & $>0.5$ & 0.15 & 0.25 & 0.05 & 0.2 \\
\hline $4 d$ & 0.1 & 0.05 & 0.4 & 0.15 & 0.05 & 0.2 & 0.15 & 0.1 \\
\hline $4 e$ & 0.2 & 0.3 & $>0.5$ & 0.15 & 0.2 & 0.35 & 0.25 & 0.25 \\
\hline $5 a$ & $>0.5$ & $>0.5$ & $>0.5$ & $>0.5$ & 0.5 & nd & 0.5 & $>0.5$ \\
\hline $5 b$ & 0.4 & 0.5 & $>0.5$ & 0.5 & 0.35 & 0.4 & 0.3 & 0.5 \\
\hline $5 c$ & 0.4 & 0.35 & 0.2 & $>0.5$ & 0.30 & 02 & 0.25 & 0.2 \\
\hline $5 d$ & 015 & 0.1 & 0.4 & 0.1 & 0.15 & 0.05 & 0.1 & 0.2 \\
\hline $5 e$ & 0.3 & $>0.5$ & $>0.5$ & 0.5 & 0.25 & 0.25 & 0.3 & 0.4 \\
\hline $5 f$ & nd & nd & nd & nd & 0.45 & $>0.5$ & 0.4 & $>0.5$ \\
\hline $5 g$ & $>0.5$ & $>0.5$ & $>0.5$ & $>0.5$ & $>0.5$ & 0.5 & $>0.5$ & $>0.5$ \\
\hline $5 h$ & $>0.5$ & 0.5 & $>0.5$ & $>0.5$ & 0.3 & 0.35 & 0.2 & 0.25 \\
\hline $5 i$ & 0.3 & 0.5 & $>0.5$ & 0.25 & 0.25 & 0.3 & 0.3 & 0.2 \\
\hline $\begin{array}{l}\text { Amox, } \\
\text { icillin }\end{array}$ & 0.05 & $<0.05$ & nd & $<0.05$ & $<0.05$ & $<0.05$ & 0.05 & $<0.05$ \\
\hline $\begin{array}{l}\text { Kana } \\
\text { mycin }\end{array}$ & $<0.05$ & $<0.05$ & $<0.05$ & $<0.05$ & $<0.05$ & $>0.5$ & $<0.05$ & $<0.05$ \\
\hline
\end{tabular}

nd; not detected 
slightly similar to BHT. Compound (4d) with two substituted methoxy group at the ortho-position of phenol displayed inhibition percentage in DPPH assay slightly higher than ascorbic acid, while DPPH scavenging activity of compound (4c) with one substituted methoxy group at ortho phenol showed less antioxidant activity than ascorbic acid. Both compounds (4d) and (4c) showed antioxidant activity higher than compound (4b) without any ortho substituted of the phenol group as depicted in Table 4. These results are consistent with the concept that the number of hydroxyl group and the electron donating group enhance the antioxidant capacity ${ }^{5}$. Although compound (4e) have di tert butyl group flanking the $\mathrm{OH}$, it displayed DPPH inhibition percentage less than compound (4d) and that could be attributed to presence of the second tert butyl group at position para which has a detrimental effect on the antioxidant properties $^{45}$. The FRAP value of the hydrazones consistent with the DPPH results Figure 5 and it showed same sequence. $4 d>4 e>4 c>4 b$.

The DPPH scavenger activity and FRAP values of the 1,3,4-oxadiazoles(5a-i)exhibited less activities than their corresponding hydrazone and that could attributed to evanescence the $\mathrm{CONHN=CHAr}$ group which involved to enhances the antioxidant activity. However, the oxadiazoles included hydroxyl group shows antioxidant capacity more than without hydroxyl group. Furthermore, the antioxidant capacity of these oxadiazoles declined with decreases of the hindrances around the hydroxyl group of phenols. The DPPH inhibitions of oxadizoles without hydroxyl substituted (5a,5f and $5 \mathrm{~g}$ ) exhibited antioxidant ability depend on the substituted group and it takes the following order 4-Me> 4-OMe>4-Cl. The FRAP value of these oxadiazoles was in agreement with the DPPH inhibition percentage as shown in Figure 5.

\section{Antibacterial activity}

The antibacterial activities for synthesized compounds were screened by micro broth dilution assays. Standard strains of Gram-negative and Gram-positive bacteria were used. Amoxicillin and Kanamycin were used as references. Minimum inhibitory concentrations ((MIC) $\mathrm{mg} / \mathrm{mL}$ ) of the synthesized compounds against the test microorganisms were established and the results were tabulated in Table 5 . Most of synthesized compounds displayed significant antibacterial activity against gram positive bacteria, while few compounds exhibited significant activities against gram negative bacteria. The results showed the relationships between the structure and the reactivity against microorganisms. The 1,3,4-oxadiazole5-thione(2) gave significant anti-bacterial activity towered gram positive and negative bacteria while this reactivity decreased with their alkyl derivatives (3a-e). This result shows that the hydroxyl group of phenol and thioamide group are play an important role to enhance the anti-bacterial activity. Compound (3b)exhibited highest activity among the thio alkyl derivative and that could be attributed to the existence of the benzimidazole group. Compound (3a) with thio ethyl group do not exhibited any activity towered any microorganisms under the test as well compound (3d). Although, compounds (3c) and (3e) consist aromatic group in their alkyl structure exhibited low activity against Gram-positive bacteria. These results represented the relationship between the structure and the anti-bacterial activities. Furthermore, the biological activity of compounds (4a-e) clearly demonstrated this relationship between the structure and the anti-bacterial activities. The anti-bacterial activity enhances with the existence of hydroxyl group of phenol in hydrazone as well the methoxy group at ortho position of the phenol. Compound (4a) showed the lowest activity (with 4-methyl substituted), while the antibacterial activity increased when the substituted was $4-\mathrm{OH}$ as in compound (4b). Compound (4c) showed higher reactivity than (4d)with one methoxy group at ortho position of phenol. The significant anti-bacterial activity against (gram negative and gram positive) appeared with compound (4d) which is possessing two methoxy groups at ortho position. The reactivity decreased with compound (4e) compared to (4d), this believed to be due to the effect of the steric hindrance of tert-butyl group at ortho position of phenol which reduced the effect of hydroxyl group and reduce their toxophoric effect . The 2,5-disubstituted1,3,4-oxadiazoles (5a-i) showed antibacterial activity slightly less than the hydrazones. The minimum inhibitory concentrations of these compounds demonstrated the importance of the effect of increasing the hydroxyl and the effect of methoxy group as well. Compounds (5d) and $(5 \mathrm{c})$ exhibited the highest activity against both gram positive and negative bacteria flowed by compounds (5b) and (5i). Even though, compound 
(5h) possesses high antioxidant activity, while their antibacterial was lower than compounds(5d), (5c) and (5b). Furthermore, the activity of compound (5d) was higher than compound (5c), and compound (5b) higher than (5h). These results clearly exhibited that the antibacterial activity depend on the toxophoric of phenol and the hindrances of this phenol constringe the toxophoric effect and the antibacterial effect doesn't correlate with the antioxidant activity of the synthesized compounds.

\section{CONCLUSION}

Two Series of 1,3,4-oxadiazole bearing 2-methyl phenol were successfully synthesized. The first one, 6-(5-thio-1,3,4-oxadiazol-2-yl)-2methylphenol (2) and their thioalkyl(3a-e). The second of 6-(5-(Aryl)-1,3,4-oxadiazol-2-yl)-2-methylphenol (5a-i)were synthesized by two methods firstly from cyclization their corresponding hydrazones(4a-e) secondly from cyclization the hydrazide(2) with arylcarboxylic acid in the presence of $\mathrm{POCl}_{3}$. The antioxidant activities of the newly synthesized compound were tested by DPPH and FRAP. Results showed the close relationship between structure and antioxidant ability. The antibacterial activities for these compounds were tested against eight of microorganisms (gram negative and gram positive). The results demonstrated that the increasing of free phenol as well the methoxy group near by the hydroxyl of phenol enhances the antibacterial activity while, the increase in the hindrance around the hydroxyl of phenollower the antibacterial activity.

\section{ACKNOWLEDGMENT}

The authors would like to acknowledge University of Baghdad for supported this research, as well great thanks to University of Malaya for their great help.

\section{REFERENCES}

1. Shacter, E. Drug Metabolism Reviews 2000, 32, 307.

2. Sangeetha, P.; Das, U. N.; Koratkar, R.; Suryaprabha, P. Free Radic Biol Med. 1990, 8, 15.

3. Chatterjee, R.; Bandyopadhyay, U.; Mazumdar, A.; Banerjee, R. K. Biochem Pharmacol. 1996, 52, 1169.

4. Khalil, Z.; Khodr, B. Free Radic Biol Med. 2001, 31, 430.

5. Kar, S., Subbaram, S., Carrico, P M., Melendez, J A. Respir Physiol Neurobiol. 2010, 174, 299.

6. Mullican, M. D.; Wilson, M. W.; Connor, D. T.; Kostlan, C. R.; Schrier, D. J.; Dyer, R. D. J. Med. Chem 1993, 36, 1090.

7. Ye, X.; Zhou, W.; Li, Y.; Sun, Y.; Zhang, Y.; Ji, H.; Lai, Y. Cancer Chemotherapy and Pharmacology 2010, 66, 277.

8. Lin CC, H. P. Phytotherapy Research 2000 , 14, 489.

9. Chattopadhyay, M. K. Current Science 2003, 85, 121 .

10. Hung, C.-Y.; Yen, G.-C. J. Agric. Food Chem. 2002, 50, 2993.

11. Raied M. Shakir; Azhar Ariffin; Mahmood
Ameen Abdulla Molecules 2014, 19, 3436.

12. Ju-Mi Jeong, S.-K. K., In-Hwa Lee, Ji-Yoon Lee, Hyuk Jung, and Cheol-Hee Choi J Pharm Pharmaceut Sci 2007, 10, 537.

13. Edge, R.; McGarvey, D. J.; Truscott, T. G. Journal of Photochemistry and Photobiology B: Biology 1997, 41, 189.

14. Bakhshandeh, G. R.; Khorasani, M. T. Iranian Journal of Polymer Scince \& Technology 1992 , $1,62$.

15. Tetsuto Kajiyama, Y. O. Polymer Degradation and Stability 2001, 71, 445.

16. Bondock, S.; Adel, S.; Etman, H. A.; Badria, F. A. European Journal of Medicinal Chemistry2012, 48, 192.

17. Zhao, J.-J.; Wang, X.-F.; Li, B.-L.; Zhang, R.-L.; Li, B.; Liu, Y.-M.; Li, C.-W.; Liu, J.-B.; Chen, B.-Q. Bioorganic \& Medicinal Chemistry Letters 2016, 26, 4414.

18. Taha, M.; Ismail, N. H.; Imran, S.; Rokei, M. Q. B.; Saad, S. M.; Khan, K. M. Bioorganic \& Medicinal Chemistry 2015, 23, 4155.

19. Nagalakshmi, G. Indian J Pharm Sci. 2008, 70, 49.

20. Rajak, H.; Kharya, M. D.; Mishra, P. Yakugaku zasshi journal of the Pharmaceutical Society 
of Japan 2007, 127, 1757.

21. Abd-Ellah, H. S.; Abdel-Aziz, M.; Shoman, M. E.; Beshr, E. A. M.; Kaoud, T. S.; Ahmed, A.-S. F. F. Bioorganic Chemistry 2016, 69, 48.

22. He, H.; Wang, W.; Zhou, Y.; Xia, Q.; Ren, Y.; Feng, J.; Peng, H.; He, H.; Feng, L. Bioorganic \& Medicinal Chemistry 2016, 24, 1879.

23. Zoumpoulakis, P.; Camoutsis, C.; Pairas, G.; Sokoviæ, M.; Glamoèlija, J.; Potamitis, C.; Pitsas, A. Bioorganic \& Medicinal Chemistry 2012, 20, 1569.

24. Urja D. Nimbalkar, S. G. T., Julio A. Seijas Vazquez, Firoz A. Kalam Khan, Jaiprakash N. Sangshetti and Anna Pratima G. Nikalje molecules 2016, 21, 484.

25. Musad, E. A.; Mohamed, R.; Ali Saeed, B.; Vishwanath, B. S.; Lokanatha Rai, K. M. Bioorganic \& Medicinal Chemistry Letters 2011, 21, 3536.

26. Ma, L.; Xiao, Y.; Li, C.; Xie, Z.-L.; Li, D.-D.; Wang, Y.-T.; Ma, H.-T.; Zhu, H.-L.; Wang, M.-H.; Ye, Y.-H. Bioorganic \& Medicinal Chemistry 2013, 21, 6763.

27. Ibrahim, S. R. M.; Mohamed, G. A.; Zayed, M. F.; Ross, S. A. Bioorganic Chemistry.

(28) Ohkatsu, Y.; Nishiyama, T. Polymer Degradation and Stability 2000, 67, 313.

29. Medina, I.; Gallardo, J. M.; González, M. J.; Lois, S.; Hedges, N. Journal of Agricultural and Food Chemistry 2007, 55, 3889.

30. Shakir, R. M. Orient. J. Chem. 2016, 32, 2611.

31. ALI, K. F. Orient. J. Chem. 2014, 31, 239.

32. HUSSAIN, D. F. Orient. J. Chm. 2016, 32, 539.

33. Gerhäuser, C.; Klimo, K.; Heiss, E.; Neumann,
I.; Gamal-Eldeen, A.; Knauft, J.; Liu, G.-Y.; Sitthimonchai, S.; Frank, N. Mutation Research/ Fundamental and Molecular Mechanisms of Mutagenesis 2003, 523-524, 163.

34. Benzie, I. F.; Strain, J. J. Anal. Biochem. 1996, 239, 70.

35. Wayne, Ed. PA, USA, 2006; Vol. 26.

36. E. A. Braude, A. G. B. a. R. P. L. J. Chem. Soc 1954, 3574.

37. Brand-Williams, W.; Cuvelier, M. E.; Berset, C. LWT - Food Science and Technology 1995, 28, 25.

38. Velkov, Z.; Balabanova, E.; Tadjer, A. Journal of Molecular Structure: 2007, 821, 133

39. Ozdem S; Alicigüzel Y; Ozdem, S. S.; Karayalçin, U. Pharmacology 2000, 61, 31.

40. Arora, R. K.; Kaur, N.; Bansal, Y.; Bansal, G. Acta Pharmaceutica Sinica B 2014, 4, 368.

41. Mavrova, A. T.; Yancheva, D.; Anastassova, N.; Anichina, K.; Zvezdanovic, J.; Djordjevic, A.; Markovic, D.; Smelcerovic, A. Bioorganic \& Medicinal Chemistry 2015, 23, 6317.

42. Neochoritis, C. G.; Zarganes-Tzitzikas, T.; Tsoleridis, C. A.; Stephanidou-Stephanatou, J.; Kontogiorgis, C. A.; Hadjipavlou-Litina, D. J.; Choli-Papadopoulou, T. European Journal of Medicinal Chemistry 2011, 46, 297.

43. Shahidi, F. Natural Antioxidants: Chemistry, Health Effects, and Applications; ACOS,: USA 1997.

44. Lucarini, M.; Pedrielli, P.; Pedulli, G. F.; Cabiddu, S.; Fattuoni, C. The Journal of Organic Chemistry1996, 61, 9259.

45. Rosenwald, R. H.; Hoatson, J. R.; Chenicek, J. A. Industrial \& Engineering Chemistry1950, $42,162$. 